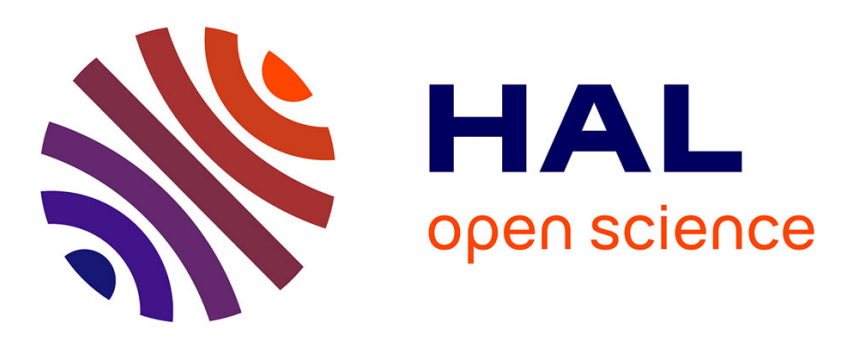

\title{
Investigation of a granular Bond number based rheological model for polydispersed particulate systems
}

Martin Giraud, Cendrine Gatumel, Stéphane Vaudez, Guillaume

Bernard-Granger, Jeremy Nos, Thierry Gervais, Henri Berthiaux

\section{- To cite this version:}

Martin Giraud, Cendrine Gatumel, Stéphane Vaudez, Guillaume Bernard-Granger, Jeremy Nos, et al. Investigation of a granular Bond number based rheological model for polydispersed particulate systems. Chemical Engineering Science, 2020, 228, pp.1-16/115971. 10.1016/j.ces.2020.115971 . hal02953369

\section{HAL Id: hal-02953369 \\ https://imt-mines-albi.hal.science/hal-02953369}

Submitted on 30 Sep 2020

HAL is a multi-disciplinary open access archive for the deposit and dissemination of scientific research documents, whether they are published or not. The documents may come from teaching and research institutions in France or abroad, or from public or private research centers.
L'archive ouverte pluridisciplinaire HAL, est destinée au dépôt et à la diffusion de documents scientifiques de niveau recherche, publiés ou non, émanant des établissements d'enseignement et de recherche français ou étrangers, des laboratoires publics ou privés. 


\title{
Investigation of a granular Bond number based rheological model for polydispersed particulate systems
}

\author{
Martin Giraud ${ }^{\mathrm{a}, \mathrm{b}}$, Cendrine Gatumel ${ }^{\mathrm{a}}$, Stéphane Vaudez ${ }^{\mathrm{b}}$, Guillaume Bernard-Granger ${ }^{\mathrm{b}}$, Jeremy Nos ${ }^{\mathrm{c}}$, \\ Thierry Gervais ${ }^{\mathrm{d}}$, Henri Berthiaux ${ }^{\mathrm{a}, *}$ \\ a Laboratoire RAPSODEE, UMR CNRS 5302, IMT Mines Albi, Campus Jarlard, 81013 Albi Cedex 09, France \\ ${ }^{\mathrm{b}}$ CEA, DEN, DMRC, Université de Montpellier, Marcoule, France \\ 'Orano, 125 avenue de Paris, 92320 Châtillon, France \\ d Orano Melox, Les Tourettes, D138A, 30200 Chusclan, France
}

\begin{abstract}
- Link between the particles properties and the flow behavior of powders.
- Dimensionless granular Bond number for polydispersed powders.

- The flowability of various powders is measured with a shear cell tester.

- Correlation between the Bond number and the flowability found experimentally.

- Physical meaning of the correlation througg Rumpf's theory.
\end{abstract}

Keywords:

Powder rheology

Flowability

Shear test

Population dependent granular Bond

number

\begin{abstract}
A B S T R A C T
Granular materials are used in many industrial processes among various fields, such as pharmaceutical, food, metallurgy or nuclear fuel production. However, compared to other commonly used media, such as liquids, powders are known to behave unpredictably, leading to uncontrolled process operations. Since the flow behavior of the powders originates from interparticle forces, we suggest a model, linking the macroscopic flowability of powder beds, and the properties of the microscopic particles constituting the powder. A population dependent granular Bond number (Capece et al., 2016), that takes into account the particles properties such as the particles' true density, surface energy, rugosity and the whole particle size distribution, is used. This non-dimensional number was found to correlate well with the flowability of polydispersed powder bed, which can be measured by shear testing with a Freeman FT4 ${ }^{\circledR}$ powder rheometer. The results found in previous studies (Bernard-Granger et al., 2019; Capece et al., 2016) are extended and discussed using five different oxide powders exhibiting various flow behaviors. In particular, a short sensitivity analysis of the model is carried out. The results show that the fraction of fine particles within a polydispersed powder is a critical parameter for the flowability of the powder bed. Finally, the Rumpf's theory is used to suggest a physical meaning for the model parameters.
\end{abstract}

\section{Introduction}

Flow behavior of powders is critical in many industrial processes involving granular materials such as pharmaceutical and chemical production or metal and mineral processing. Indeed, a poor flowability may lead to various problems such as segregation, agglomeration or arching during bulk powder handling or processing.

\footnotetext{
* Corresponding author.

E-mail address: henri.berthiaux@mines-albi.fr (H. Berthiaux).
}

Up to now, the link between the physicochemical properties of the individual particles and the flowability of bulk powders is still unclear. This is because granular materials exhibit highly variable and unpredictable behaviors. It is generally considered that under a certain size, around $100 \mu \mathrm{m}$, interparticle attractive forces start to overcome particles' weight, resulting in cohesive behaviors (Aulton, 2002). However, flowability is not only correlated to particles' size but is also influenced by particles' shape (Cleary, 2008; Podczeck and Mia, 1996), surface energy, mechanical properties (Tomas, 2001), environmental conditions (Tomasetta et al., 2014) 
and polydispersity of the particle size distribution (Vlachos and Chang, 2011).

Since a cohesive behavior originates from interparticle attractive forces, many efforts are undertaken in order to correlate intermolecular forces, such as Van der Waals, capillarity and electrostatic forces, to the bulk powder behavior. Therefore, flowability criterions based on the preponderance of either gravity or interparticle forces between individual particles were proposed (Li et al., 2004; Liu et al., 2008). Models assessing the flow performance of powders from the force balance at an individual particle level were then derived (Li et al., 2004; Liu et al., 2008; Tomasetta et al., 2014). Although these models seems to be in good agreement with empirical data, they are not commonly used for predictions since they involve very specific particles' properties, such as the Poisson's ratio or the Young's modulus, which are not always measurable. It can also be noticed that most of these models are based on the assumption that the particle properties are identical within the whole powder. However, in most granular mediums, various particle properties, such as the size, shape or surface energy, may be actually distributed (Arai, 1996).

The granular Bond number is defined as the ratio between interparticle forces and gravity contribution between two particles, A and B on Fig. 1 for example. It can be computed from quite simple particle properties, such as size distribution, particles' rugosity, surface energy and true density, which are easily measurable or documented in the literature. Assuming that the electrostatic and capillary forces can be neglected, the interparticle forces are equal to the Van der Waals forces developed between the particles. The granular Bond number between particles $\mathrm{A}$ and $\mathrm{B}\left(B o_{g, A B}\right)$ can then be expressed using Eq. (1):

$B o_{g, A B}=\frac{F_{v d w, A B}}{W_{A B}}$

where $F_{v d w, A B}$ is the Van der Waals force and $W_{A B}$ is the weight of the particles. The Van der Waals force can be assessed from particle properties using commonly known cohesion force models (Hamaker, 1937; Rumpf, 1990; Xie, 1997; Chen et al., 2008; Rabinovich et al., 2000; Derjaguin et al., 1975; Johnson et al., 1971). In particular, the Van der Waals Force between two spherical particles may be estimated using Eq. (2) from the Hamaker theory (Hamaker, 1937):

$F_{v d w, A B}=\frac{\sqrt{A_{A} A_{B}}}{12 z_{0}^{2}} \frac{d_{A} d_{B}}{d_{A}+d_{B}}$

where $A_{A}$ and $A_{B}$ are the Hamaker constants of particles $\mathrm{A}$ and $\mathrm{B}$ respectively, $d_{A}$ and $d_{B}$ are the diameter of particles $A$ and $B$ respectively, and $z_{0}$ is the distance between the two particles in close contact which can be assumed to be $z_{0}=0.4 n m$ (Israelachvili, 2011a). Since real powders are rarely constituted of spherical and smooth

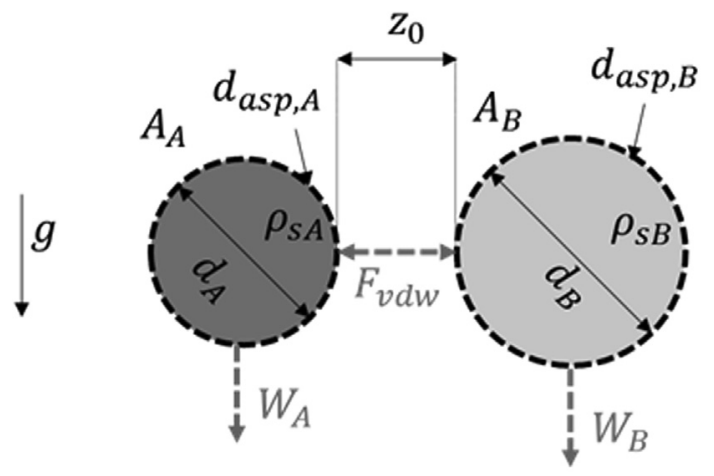

Fig. 1. Forces applied between two spherical particles A and B in close contact. particles, the rugosity of particles $A$ and $B$ can be taken into account by using the modified Rumpf equation (3), which shows a better agreement with empirical data (Chen et al., 2008):

$F_{v d w, A B}=\frac{\sqrt{A_{A} A_{B}}}{12 z_{0}^{2}}\left(\frac{\widehat{d}}{2\left(1+\frac{\widehat{d}_{a s p}}{2 z_{0}}\right)^{2}}+\frac{3 \widehat{d}_{a s p} \widehat{d}}{\widehat{d}_{a s p}+\widehat{d}}\right)$

In the above equation, $\widehat{d}$ is the harmonic mean diameter of particles A and B. Similarly, $\widehat{d}_{a s p}$ is the harmonic mean of the size of asperities of particles A and B. It was shown in the literature that $d_{a s p}=200 \mathrm{~nm}$ is a reasonable approximation for the size of natural roughness of powders (Capece et al., 2015).

The geometric mean of the weight of particles $A$ and $B$ is used to represent the weight of both particles $\left(W_{A B}\right)$ in Eq. (1) (Capece et al., 2016). The true density of particles $A$ and $B$, respectively $\rho_{s, A}$ and $\rho_{s, B}$, allow to compute the weight of the particles, represented by the powder's true density, as shown in Eq. (4):

$W_{A B}=\frac{\pi}{6} g \sqrt{\rho_{s, A} \rho_{s, B} d_{A}^{3} d_{B}^{3}}$

where $g=9.81 \mathrm{~m} \cdot \mathrm{s}^{-2}$ is the gravity constant.

In case of two particles in close contact within a monoconstituent powder, particles A and B are of the same chemical nature, which means that they share approximately the same Hamaker constant, true density and asperity diameters. The granular Bond number between these two particles can then be computed using Eq. (5):

$B o_{g, A B}=\frac{A}{2 \pi \rho_{s} g z_{0}{ }^{2}} \times \frac{\widehat{d}}{\sqrt{d_{A}{ }^{3} d_{B}^{3}}}\left(\frac{1}{2\left(1+\frac{d_{a s p}}{2 z_{0}}\right)^{2}}+\frac{3 d_{a s p}}{d_{a s p}+\widehat{d}}\right)$

where $A$ is the Hamaker constant of the powder, $\rho_{s}$ is its true density and $\widehat{d}=2 \frac{d_{A} d_{B}}{d_{A}+d_{B}}$.

Despite the fact that it only accounts for individual interparticle cohesion, and not for the whole bulk powder bed structure, the granular Bond number was shown to correlate well with the flow behavior for cohesive powders. Castellanos (Castellanos, 2005) noticed a link between the granular Bond number and the bulk properties of powders, such as the gas velocity over which the fluidized bed exhibits non-bubbling regime. He also proposed an agglomerate Bond number, which takes into account the agglomeration events occurring within fine powders. This concept of granular and agglomerate Bond numbers are also used by Huang (Huang et al., 2015) who showed that the flow function coefficient, measured with a powder shear tester, evolves with the Bond number according to a power law. The same type of correlation was highlighted and further explored by Capece (Capece et al., 2015). In particular, a population dependent granular Bond number was developed (Capece et al., 2016) in order to take into account the whole particle size distribution of the powder investigated. Indeed, the granular Bond number allows to consider distributed properties, while most anterior models only considered means or median properties, assuming that particles' size or shape are identical for all the particles constituting the powdered medium. Finally, Capece's granular Bond number and population dependent granular Bond number have also been extended to multi-component mixture of powders (Capece et al., 2015).

The correlation obtained by Capece between the flow function coefficient and the granular Bond number of pharmaceutical powders, is a power law given by Eq. (6). In this equation, the empirical parameters $\alpha$ and $\beta$ are supposed to be material independent. $f f_{c}$ 
corresponds to the flow function coefficient, also denoted as the flow index in this paper, and $\mathrm{Bo}_{\mathrm{g}}$ is the granular Bond number.

$f f_{c}=\alpha \cdot B o_{g}{ }^{-\beta}$

Such a correlation has also been verified experimentally by investigating the rheological behavior of powder mixtures constituted by different amounts of two alumina powders (BernardGranger et al., 2019).

The correlation represented by Eq. (6) was obtained by Capece for various pharmaceutical powders and with multi-component mixtures involving these powders. Although the powders investigated exhibit different flow behaviors, from very poor flowability to free flowing, most of them share a similar true density, between 1 and $3 \mathrm{~g} . \mathrm{cm}^{-3}$ while powders used in other fields may be heavier. Moreover, Capece used an RST-XS ${ }^{\circledR}$ Schulze shear tester to measure the flowability of the powders, while different equipment, such as the FT $4^{\circledR}$ Freeman's rheometer, are becoming commonly used (Leturia et al., 2014). Even if these two equipment are based on the same principle, it is well known that they differ in some aspects that may affect the results (Koynov et al., 2015). Among other things, the RST-XS ${ }^{\circledR}$ Schulze and the FT $4{ }^{\circledR}$ Freeman rheometer cannot apply the same pre-consolidations stress, although it was shown that the consolidation state of the powder might affect the flowability measurements (Legoix et al., 2017). Thereby, it appears that the correlation found by Capece needs to be verified and extended using different powders and different types of rheometer.

Since most investigations focus only on the Van der Waals force contributions for the calculation of interparticle forces, BernardGranger attempted to take also into account the capillary forces in the calculation of the granular Bond number (Bernard-Granger et al., 2019). However, this study was done with alumina powders that appear to be sparsely sensitive to relative humidity. Then, the influence of capillary forces has to be discussed for powders that are more sensitive to humidity as well.

Both authors show that the correlation (6) obtained between the granular Bond number and the flowability of powders has a strong potential for predicting the flowability of powder mixtures according to their formulation (Bernard-Granger et al., 2019; Capece et al., 2015). However, despite its good ability to predict the flowability of powders and mix of powders, the physical meaning of the correlation has never been investigated extensively. In particular, the value of the correlation parameters $\alpha$ and $\beta$, that are supposed to be material independent, is poorly discussed. Besides, it is well known that the consolidation state of a powder bed affects significantly the flowability measurements (Legoix et al., 2017; Tomasetta et al., 2014). Then, the effect of the preconsolidation stress, applied to the powder during shear testing, on the correlation parameters has to be investigated. Finally, a sensitivity analysis of the correlation has never been carried out in the literature although it has to be done out in order to evaluate the relevance of the predictive model. In particular, since the granular Bond number depends on various particle's properties, it would be of a great interest to assess which parameter is the most influent on its value, and therefore on the flowability of the bulk powder medium.

In this paper, Capece's model will be extended, by comparing experimental results obtained with an FT $4^{\circledR}$ powder rheometer, to the model predictions for non-pharmaceutical powders exhibiting various properties in terms of flow behavior, true density, particle size distributions or sensibility to relative humidity. Besides, a sensitivity analysis of the granular Bond number will be carried out in order to investigate the influence of different powder properties on the value of the granular Bond number. First, the influence of non-distributed properties, such as the true density, will be stud- ied. Then, the influence of distributed properties, such as particle size distribution, will be investigated in order to take into account the polydispersity of real powders. Then, the physical meaning of the correlation (6) linking the flowability of bulk powders and the granular Bond number, will be discussed. In particular, a physical interpretation of the value of empirical parameters $\alpha$ and $\beta$, involving the state of consolidation of the powder, will be suggested.

\section{Materials and methods}

\subsection{Powders}

Five different powders have been used for this work. They were chosen because they all exhibit different properties in terms of flow behavior, particle size and shape distribution, true density and bed porosity:

- Two different grades of alumina powder (GE15 and CR6) from Baikowski $^{\circledR}$, Poisy, France.

- Two different grades of zirconia powder (GY3Z-R60 and CY3ZRA) from Saint Gobain ${ }^{\circledR}$, Courbevoie, France.

- An yttrium oxide powder (grade C) from H.C. Starck ${ }^{\circledR}$, Newton, USA.

In this paper, alumina GE15, alumina CR6, zirconia GY3Z-R60, zirconia CY3Z-RA and yttria grade $\mathrm{C}$ will be referred as $\mathrm{Al}_{2} \mathrm{O}_{3} \mathrm{G}$, $\mathrm{Al}_{2} \mathrm{O}_{3} \mathrm{C}, \mathrm{ZrO}_{2} \mathrm{G}, \mathrm{ZrO}_{2} \mathrm{C}$ and $\mathrm{Y}_{2} \mathrm{O}_{3} \mathrm{C}$ respectively.

\subsection{Characterization methods}

Each powder has been characterized in terms of flow behavior, particle size distribution, true density and surface energy. Then, the granular Bond number has been computed for all powders using the methodology described in section 2.3.

\subsubsection{Powder flowability}

The flowability of the powders was assessed from the yield locus measured with a powder rheometer FT $4^{\circledR}$ (Freeman, Tewkesbury, UK). Measurements were performed using a $10 \mathrm{~mL}$ cylindrical cell in which powder is pre-consolidated under a $9 \mathrm{kPa}$ normal stress. Shear tests are then performed successively at 3, 4, 5, 6 and $7 \mathrm{kPa}$ normal stresses following the Jenike standard procedure (EFCE Working Party on the Mechanics of Particulate Solids. and Institution of Chemical Engineers (Great Britain), 1989). According to Mohr's theory, the five points obtained should be aligned on the yield locus line, represented on Fig. 2, whose parametric equation is given by Eq. (7):

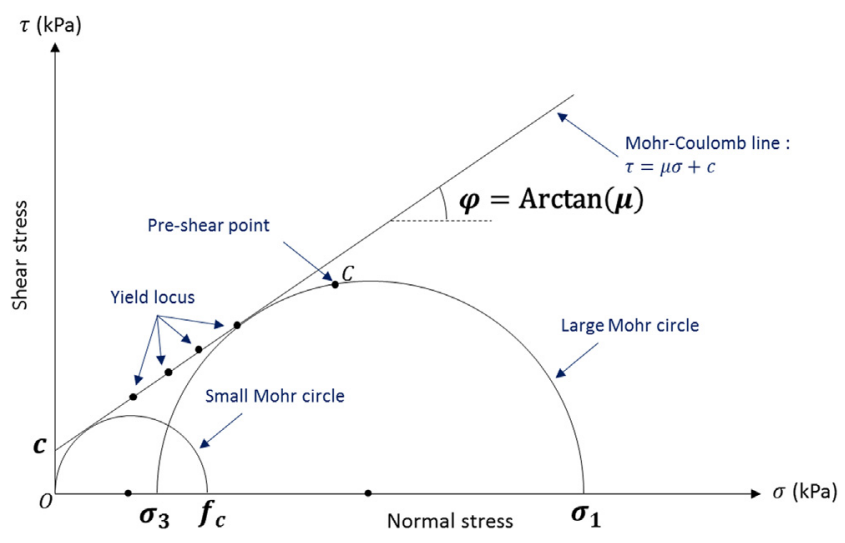

Fig. 2. Mohr-Coulomb yield locus and Mohr circles. 
$\tau=\mu \sigma+c$

where $\tau$ and $\sigma$ are respectively the shear and the normal stresses. $c$ gives the cohesion of the powder in $\mathrm{kPa}$, and $\mu$ is the friction coefficient from which the angle of internal friction $\varphi$ can be deduced using Eq. (8). The friction coefficient comes from friction between the surfaces of the particles while cohesion originates from interparticle forces taking place between particles.

$\mu=\tan \varphi$

The Mohr circles can then be constructed from the yield locus curve, as shown on Fig. 2. The small Mohr circle is tangent to the yield locus and passes through the origin while the large Mohr circle is tangent to the yield locus and passes through the pre-consolidation point. The cohesion stress $f_{c}$ and the major consolidation stress $\sigma_{1}$ corresponds to the shear stress values of the highest intersections between the $\mathrm{x}$-axis and the small and large Mohr circles respectively. The flow index, which is given by Eq. (9), is used in order to assess the flowability of a powder, the classification given in Table 1 being commonly used in the literature to classify the flow behavior of a given powder (Leturia et al., 2014).

$f f_{c}=\frac{\sigma_{1}}{f_{c}}$

The flow index $f f_{c}$ and cohesion $c$, measured by shear tests for each powder, are reported in Table 2. Each measurement was performed at least twice with different samples, the incertitude given in the table corresponding to the standard deviation. The first column shows results for powders in ambient conditions, while the second column shows results obtained for the same powders after drying in a stove at $110{ }^{\circ} \mathrm{C}$ for $24 \mathrm{~h}$. The moisture content of the powders in ambient conditions was measured with an $\mathrm{MB90}^{\circledR}$ moisture analyzer (Ohaus, Parsippany, USA) by heating the samples at $110{ }^{\circ} \mathrm{C}$ for two minutes. The results showed that all the powders had a moisture content between $0.2 \%$ and $0.5 \%$ in natural ambient conditions. The flow index of the dry $\mathrm{ZrO}_{2} \mathrm{G}$ powder was not calculated because its flowability is too high for the equipment under that level of consolidation. Indeed, for this specific powder, the rheometer gives a cohesion parameter slightly below zero, which has no physical meaning. Thus, the cohesion of the $\mathrm{ZrO}_{2} \mathrm{G}$ was assumed to be $0 \mathrm{kPa}$, corresponding to a free flowing powder, and its flow index is not calculated. Concerning the other powders, it can be noted that the flowability of the dry and ambient powders are very similar for alumina and yttrium oxide while it differs significantly for both zirconia powders. This means that powders of different nature may react differently to ambient humidity. For this reason, all the samples were conditioned in a stove before any measurement with the rheometer. Fig. 3 shows the flow index of each dry and wet powders according to their cohesion. It seems that these two parameters are strongly correlated according to a power law which parameters are given in Eq. (10), where the cohesion parameter $c$ is in $\mathrm{kPa}$, through a determination coefficient of $R^{2}=0.9993$.

$f f_{c} \approx 4.66 \times c^{-0.90}$

Table 1

Classification of the flowability of powders according to the flow index value.

\begin{tabular}{ll}
\hline Flow index value & Flowability \\
\hline$f f_{c}<1$ & Not flowing \\
$1<f f_{c}<2$ & Very poor \\
$2<f f_{c}<4$ & Poor \\
$4<f f_{c}<10$ & Easy \\
$f f_{c}>10$ & Free flowing \\
\hline
\end{tabular}

\subsubsection{True density}

The true density of the particles $\rho_{s}$ was measured using a helium pycnometer AccuPyc II $1340^{\circledR}$ (Micromeritics, Mérignac, France) in a $10 \mathrm{~mL}$ cell. Five samples per powder were taken and measured, the average result being kept for each powder. Between three and six cycles including of 25 purges and 25 measurements were performed on each powder at $23{ }^{\circ} \mathrm{C}$ and $19.6 \mathrm{PSI}(135 \mathrm{kPa})$. Results are given in Table 4 where the incertitude corresponds to the standard deviations between different samples.

\subsubsection{Particle size distribution}

Particle size distributions of the powders were measured with a LASER diffraction equipment Mastersizer $3000^{\circledR}$ (Malvern, Malvern, UK) using a liquid dispersion unit (Hydro $\mathrm{MV}^{\circledR}$ ) in order to obtain adequate dispersion of the agglomerated powders. Dry dispersion (Aero $S^{\circledR}$ ) has also been performed but the particle size distribution is too variable and highly dependent on the transport pressure through the venturi. The Mie theory was used in order to compute the size of the particles. Ten samples per powder were analyzed and a measurement was taken ten times for each sample. The Sauter mean diameter and the span of the distributions are given in Table 4. The average of each measurements was kept and the incertitude intervals correspond to the standard deviation. The particle size distribution of each powder is given on Fig. 4. It should be noted that the powders exhibiting the worse flowability values in Table $2\left(\mathrm{Al}_{2} \mathrm{O}_{3} \mathrm{C}\right.$ and $\left.\mathrm{Y}_{2} \mathrm{O}_{3} \mathrm{C}\right)$ are those containing the largest fraction of very fine particles, under $10 \mu \mathrm{m}$. On the contrary, the only free flowing powder according to Table $2\left(\mathrm{ZrO}_{2} \mathrm{G}\right)$ is also the only one that exhibits the most significant fraction of particles larger than $100 \mu \mathrm{m}$. Finally, $\mathrm{Al}_{2} \mathrm{O}_{2} \mathrm{G}$ and $\mathrm{ZrO}_{2} \mathrm{C}$ both have intermediate flow behavior and also intermediate particle size distributions, as compared to the other ones. The link between particle size distribution and flowability will be further explored in next sections.

\subsubsection{Particle surface energy}

Dynamic vapor sorption was performed with a DVS system (SMS, London, UK) in order to measure surface energy of the particles. The device, illustrated on Fig. 5, is constituted of a microbalance (5) placed in a thermal chamber (6), here regulated at $25^{\circ} \mathrm{C}$. Around $100 \mathrm{mg}$ of powder (2) and a reference sample (3) are placed on both sides of the balance and are swept by a gas, here nitrogen. The humidity of the gas (heptane vapor) is controlled by two valves and a humidifier (1) and measured with two probes (4) on each sides of the chamber. The humidity of the gas varies from $0 \%$ to $95 \%$ relative humidity and the mass loss is measured, giving the sorption and desorption isotherms.

The dispersive surface energy is then computed using the method described in SMS application note 17 (Levoguer and Williams, n.d.). This method was shown to give similar results than inverse gas chromatography for alumina powders (Tisserand et al., 2009). Knowing the specific surface area of the sample, the equilibrium spreading pressure $\pi_{e}$ can be deduced from the adsorption isotherm of the sample, using Gibbs theory. The value of $\pi_{e}$ allows then to compute the work of adhesion between the liquid and solid phases $w_{S L}$ from solid/liquid interaction theory described by Young's equation:

$w_{S L}=\gamma_{l}^{d}(1+\cos \theta)+\pi_{e}$

Where $\gamma_{l}{ }^{d}$ is the liquid surface tension and $\theta$ is the angle of contact between the droplet and the sloid surface. For heptane, the surface tension is well known $\left(\gamma_{l}^{d}=19.68 \mathrm{mN} \cdot \mathrm{m}^{-1}\right)$ and the contact angle can be assumed to be null. Finally, the dispersive surface 
Table 2

Flow index and cohesion parameter of the powders measured using a FT4 ${ }^{\circledR}$ powder rheometer, under ambient and dry conditions.

\begin{tabular}{|c|c|c|c|c|}
\hline \multirow[t]{2}{*}{ Material } & \multicolumn{2}{|c|}{$\begin{array}{l}\text { Ambient conditions (around } 30 \% \text { relative humidity } \\
\text { and } 23{ }^{\circ} \mathrm{C} \text { ) }\end{array}$} & \multicolumn{2}{|c|}{ Dry condition (stove at $110^{\circ} \mathrm{C}$ for $24 \mathrm{~h}$ ) } \\
\hline & $f f_{c, a m b}(-)$ & $c_{a m b}(k P a)$ & $f f_{c, d r y}(-)$ & $c_{a m b}(k P a)$ \\
\hline $\mathrm{Al}_{2} \mathrm{O}_{3} \mathrm{G}$ & $9.58 \pm 0.01$ & $0.47 \pm 0.00$ & $8.42 \pm 0.11$ & $0.54 \pm 0.01$ \\
\hline $\mathrm{Al}_{2} \mathrm{O}_{3} \mathrm{C}$ & $1.42 \pm 0.06$ & $3.73 \pm 0.07$ & $1.19 \pm 0.04$ & $4.57 \pm 0.31$ \\
\hline $\mathrm{ZrO}_{2} \mathrm{G}$ & $7.54 \pm 1.29$ & $0.56 \pm 0.11$ & - & 0 \\
\hline $\mathrm{ZrO}_{2} \mathrm{C}$ & $6.71 \pm 1.07$ & $0.65 \pm 0.11$ & $12.5 \pm 1.43$ & $0.34 \pm 0.04$ \\
\hline $\mathrm{Y}_{2} \mathrm{O}_{3} \mathrm{C}$ & $1.52 \pm 0.13$ & $3.49 \pm 0.35$ & $1.58 \pm 0.05$ & $3.32 \pm 0.14$ \\
\hline
\end{tabular}

Table 3

Surface properties of the particles, measured by dynamic vapor sorption (DVS) of heptane at $25^{\circ} \mathrm{C}$.

\begin{tabular}{|c|c|c|c|c|}
\hline Material & $\begin{array}{l}\text { Specific surface area } \\
s_{A}\left(m^{2} \cdot g^{-1}\right)\end{array}$ & $\begin{array}{l}\text { Equilibrium spreading pressure } \\
\pi_{e}\left(m N \cdot m^{-1}\right)\end{array}$ & $\begin{array}{l}\text { Work of adhesion solid / liquid } \\
w_{S L}\left(m N \cdot m^{-1}\right)\end{array}$ & $\begin{array}{l}\text { Dispersive surface energy } \\
\gamma_{s}^{d}\left(m N \cdot m^{-1}\right)\end{array}$ \\
\hline $\mathrm{Al}_{2} \mathrm{O}_{3} \mathrm{G}$ & $11,8 \pm 0.8$ & $38,0 \pm 0.8$ & $77.4 \pm 0.8$ & $76.1 \pm 1.6$ \\
\hline $\mathrm{Al}_{2} \mathrm{O}_{3} \mathrm{C}$ & 4,2 & 38,3 & 77.7 & 76.6 \\
\hline $\mathrm{ZrO}_{2} \mathrm{G}$ & $2.4 \pm 0.3$ & $25,5 \pm 1.3$ & $65.8 \pm 2.3$ & $55.2 \pm 3,8$ \\
\hline $\mathrm{ZrO}_{2} \mathrm{C}$ & 5.5 & 36,6 & 75.9 & 73.2 \\
\hline $\mathrm{Y}_{2} \mathrm{O}_{3} \mathrm{C}$ & 10,2 & 34,5 & 73.9 & 69.3 \\
\hline
\end{tabular}

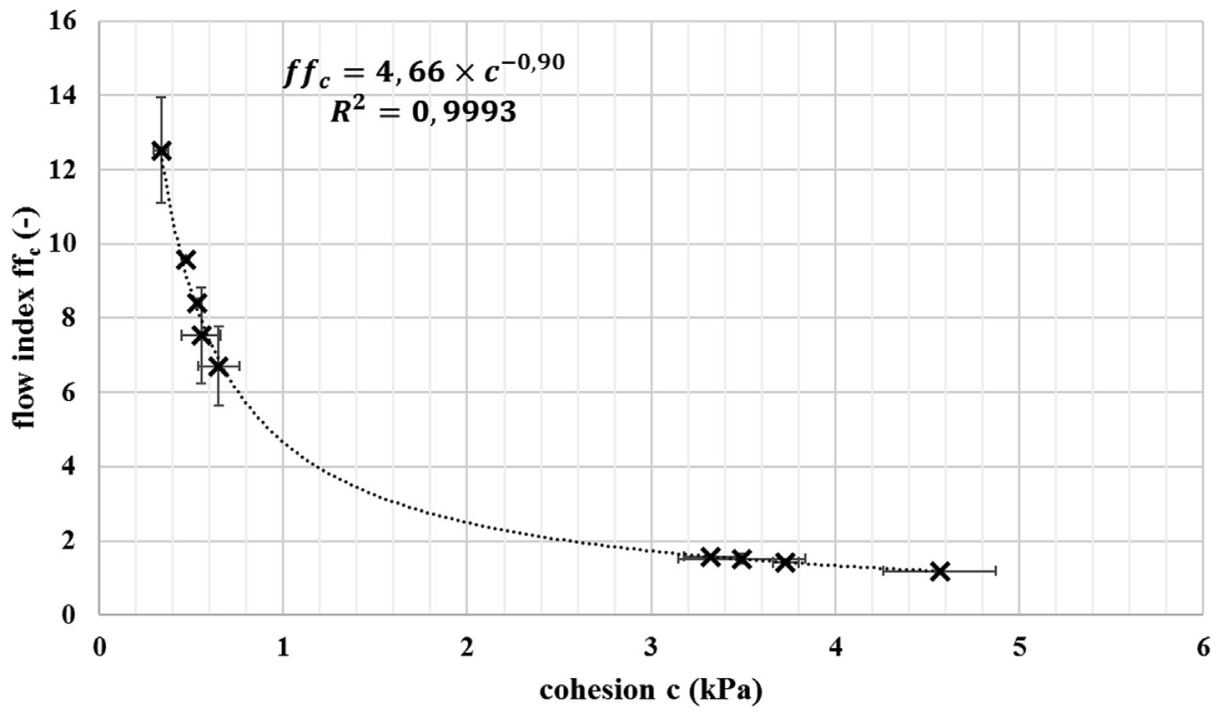

Fig. 3. Flow index of dry and wet powders according to their cohesion measured by FT4 ${ }^{\circledR}$ powder rheometer in a $10 \mathrm{~mL}$ cell, under a pre-consolidation stress of 9 kPa.

Table 4

Powders properties and population dependent granular Bond number calculated.

\begin{tabular}{|c|c|c|c|c|c|c|}
\hline Material & $\begin{array}{l}\text { True density } \\
\rho_{s}\left(\mathrm{~g} . \mathrm{cm}^{-3}\right)\end{array}$ & $\begin{array}{l}\text { Hamaker constant } \\
A\left(10^{-19} \mathrm{~J}\right)\end{array}$ & $\begin{array}{l}\text { Sauter mean diameter } \\
D_{s}(\mu m)\end{array}$ & $\begin{array}{l}\text { Span of the distribution } \\
\text { Span }(-)\end{array}$ & $\begin{array}{l}\text { Asperity size } \\
d_{a s p}(n m)\end{array}$ & $\begin{array}{l}\text { Population-dependent granular Bond number } \\
\mathrm{Bo}_{G}(-)\end{array}$ \\
\hline $\mathrm{Al}_{2} \mathrm{O}_{3} \mathrm{G}$ & $4.017 \pm 0.070$ & $1.57 \pm 0.03$ & $23.1 \pm 1.3$ & $2.07 \pm 0.10$ & 200 & $(1.16 \pm 0.05) \times 10^{2}$ \\
\hline $\mathrm{Al}_{2} \mathrm{O}_{3} \mathrm{C}$ & $4.080 \pm 0.005$ & 1.56 & $4.4 \pm 0.8$ & $4.28 \pm 1.20$ & 200 & $(1.09 \pm 0.23) \times 10^{4}$ \\
\hline $\mathrm{ZrO}_{2} \mathrm{G}$ & $5.408 \pm 0.010$ & $1.13 \pm 0.08$ & 52.6 & 2.08 & 200 & $7.40 \times 10^{0}$ \\
\hline $\mathrm{ZrO}_{2} \mathrm{C}$ & $5.874 \pm 0.012$ & 1.50 & $34.7 \pm 11.1$ & $1.04 \pm 0.06$ & 200 & $(3.39 \pm 0.66) \times 10^{1}$ \\
\hline $\mathrm{Y}_{2} \mathrm{O}_{3} \mathrm{C}$ & $4.986 \pm 0.093$ & 1.42 & $5.4 \pm 3.5$ & $13.6 \pm 5.88$ & 200 & $(2.57 \pm 1.32) \times 10^{3}$ \\
\hline
\end{tabular}

energy of the sample $\gamma_{s}^{d}$ is computed from the Fowkes model represented by Eq. (12), which is valid since the van der Waals of the powders used in this study are London dispersive interactions.

$w_{S L}=2 \sqrt{\gamma_{l}^{d} \cdot \gamma_{s}^{d}}$

The Hamaker constant can then be computed using the Frenkel equation (Israelachvili, 2011b, p. 13):

$A=24 \pi D_{0}^{2} \gamma_{s}^{d}$ where $D_{0} \approx 0.165 \mathrm{~nm}$ is a cut off distance.

DVS measurements are carried out on two different samples for $\mathrm{Al}_{2} \mathrm{O}_{3} \mathrm{G}$ and $\mathrm{ZrO}_{2} \mathrm{G}$, other powders being measured only once. The values obtained by DVS for each powders are given in Table 3 and the average Hamaker constant values and the corresponding standard deviations are summarized in Table 4. The values obtained from this method are consistent with those that can be computed from the Lifshitz theory (Bernard-Granger et al., 2019; Lifshitz and Hamermesh, 1992). 


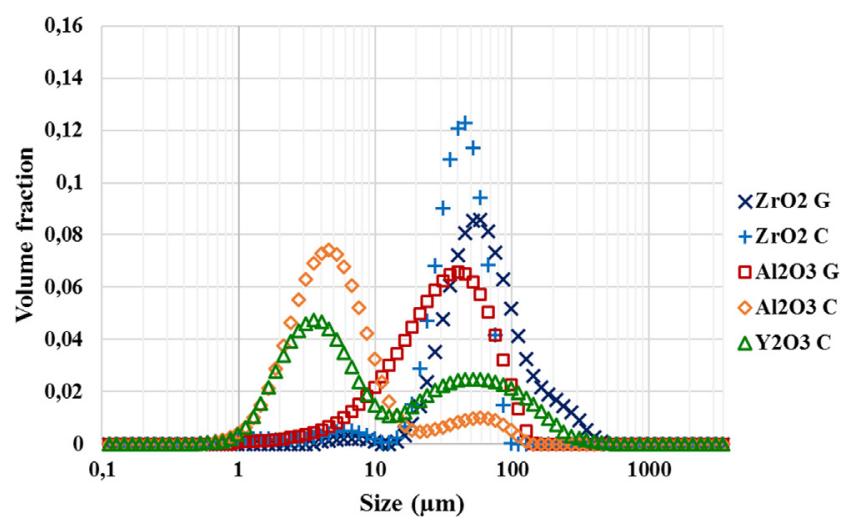

Fig. 4. Particle volume distribution of the powders measured by LASER diffraction with liquid dispersion.

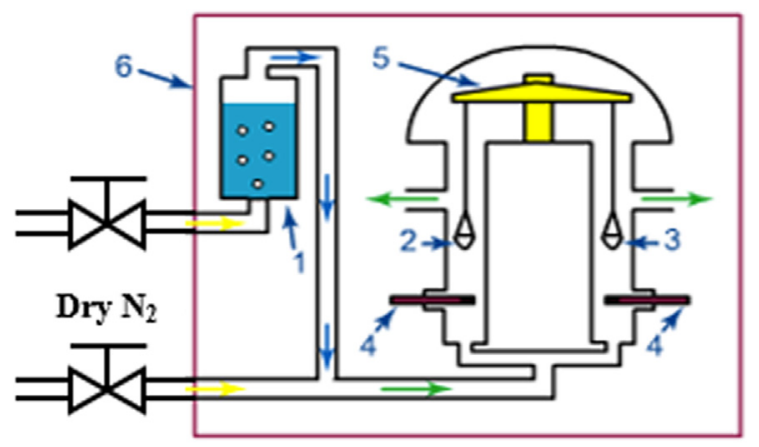

Fig. 5. Schematic representation of the DVS system.

\subsection{Population dependent granular Bond number calculation}

\subsubsection{Interparticle forces}

In this study, the capillary forces have been neglected since all the samples have been dried before rheological measurements. The electrostatic forces have been measured by a triboelectrification technique: a few grams of powder is introduced in a cylindrical vessel made of stainless steel, oriented at $40^{\circ}$ from the horizontal, isolated from the ground and rotating at 92 revolutions per minute. The total charge acquired or conceded by the powder after a certain amount of time is obtained by placing the sample in a Faraday cage, linked to an electrometer. The magnitude of the specific charge acquired or conceded by the samples never exceeds one micro Coulomb per kilogram except from the $\mathrm{Y}_{2} \mathrm{O}_{3} \mathrm{C}$ powder, which reaches $-3.8 \mu \mathrm{C} . \mathrm{kg}^{-1}$ after $15 \mathrm{~min}$ of rotation. Finally, the magnitude of the electrostatic forces within the powder, assuming that particles are in close contact, can then be estimated using Eq. (14), where $C$ is the surface charge of the particle, obtained from the specific charge of the powder and the specific surface area of the particles (Bernard-Granger et al., 2019). However, it should be noted that in this technique, the charge measured corresponds to the total charge of the sample and does not account for the individual particle electrostatic charges. Thus, this method only allows to get an order of magnitude of the effective electrostatic forces.

$\left|F_{e l}\right|^{\max }=\frac{\pi C^{2} d^{2}}{4 \varepsilon_{r} \varepsilon_{0}}$

here, $\varepsilon_{0}=8.90 \times 10^{-12} C^{2} . N^{-1} . m^{-2}$ is the vacuum dielectric constant and $\varepsilon_{r}=1$ is the relative dielectric constant of the air.
Fig. 6 shows the evolution of the electrostatic forces (Eq. (14)), the weight (Eq. (4)) and Van der Waals forces (Eq. (3)), according to the particle diameter of $\mathrm{Y}_{2} \mathrm{O}_{3} \mathrm{C}$ powder, which is the powder where the electrostatic forces are the most significant. It appears clearly that the magnitude of the electrostatic forces is negligible compared to other forces acting on the particles. Thus, the van der Waals forces are the only interparticle force taken into account for the evaluation of cohesive forces in this study.

\subsubsection{Calculation method of population dependent granular Bond number accounting for size polydispersity}

For real powders, it was shown that the Sauter mean diameter can be used in order to represent the particle size of one powder exhibiting poorly dispersed size distribution (Capece et al., 2015). However, this approximation becomes questionable when the powders exhibit more complex particle size distributions. Therefore, Capece developed a population dependent granular Bond number $\mathrm{Bo}_{G}$ allowing to take into account the whole size distribution of a powder. This population-dependent granular Bond number consists of a weighted harmonic mean of all the potential individual granular Bond numbers within the powder as shown in Eq. (15) (Capece et al., 2016).

$\left.B o_{G}=\sum_{k=1}^{M} \sum_{l=1}^{M} \frac{f_{s}\left(x_{k}\right) \cdot f_{s}\left(x_{l}\right)}{B o_{g, k l}}\right)^{-1}$

where all size classes are indexed from 1 to $M, x_{k}$ and $x_{l}$ correspond to the size of the classes $k$ and $l$ respectively and $f_{s}\left(x_{k, l}\right)$ is the surface distribution function according to the size $x_{k, l}$ which can be obtained from the volume distribution given by LASER diffraction, assuming that the particles are spherical. Finally, $B o_{g, k l}$ is the individual granular Bond number between particles of size $x_{k}$ and $x_{l}$ computed as shown in Eq. (5).

In order to compute the population dependent granular Bond number, using Eqs. (5) and (15), the true density, the Hamaker constants and the size distribution of each powder were measured. All the results are summarized in Table 4. As explained in the introduction, the asperity size can be reasonably assumed to be around $200 \mathrm{~nm}$. AFM measurements, were carried out in contact mode with a confocal Raman microscope alpha300 R (WITec ${ }^{\circledR}$, Ulm, Germany), the root mean squares observed on the surface of several particles are given in Table 5, the incertitude given corresponds to the standard deviation between several particles of the same powder (between three and six particles per powder). Despite the large deviations between different measurements and the low amount of particles analyzed, the results showed that $200 \mathrm{~nm}$ is reasonable for all the powders investigated. The last column of Table 4 gives the population dependent granular Bond number calculated for each powder. In particular, the whole granulometric distribution was used to compute the population dependent granular Bond number, but some key parameters of the size distributions are given in Table 4. The high standard deviation on the $\mathrm{Y}_{2} \mathrm{O}_{3} \mathrm{C}$ Bond number comes from the poor repeatability of the particle size measurements for this powder, due to its very wide distribution.

\section{Theoretical developments}

\subsection{Sensitivity analysis of the population dependent granular Bond} number

As shown in the introduction section 1, the granular Bond number seems to be correlated to the flowability of the powders. Besides, the population dependent granular Bond number, computed in section 2.3.2, depends on various particle properties, such 


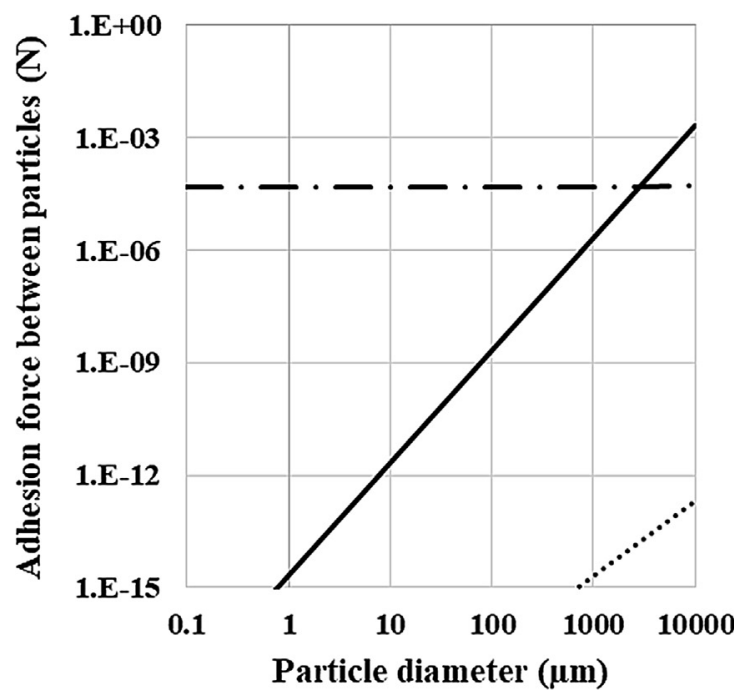

- gravitational forces

- - Van der Waals forces

Electrostatic forces

Fig. 6. Estimation of the gravity, Van der Waals and electrostatic forces of $\mathrm{Y}_{2} \mathrm{O}_{3} \mathrm{C}$ particles according to their size.

Table 5

Root mean square of the asperities measured by atomic force microscopy (AFM) on the surface of the particles.

\begin{tabular}{ll}
\hline Material & Root mean square \\
\hline & $r m s(n m)$ \\
$\mathrm{Al}_{2} \mathrm{O}_{3} \mathrm{G}$ & $195.3 \pm 17.9$ \\
$\mathrm{Al}_{2} \mathrm{O}_{3} \mathrm{C}$ & $251.6 \pm 48.5$ \\
$\mathrm{ZrO}_{2} \mathrm{G}$ & $120.9 \pm 16.1$ \\
$\mathrm{ZrO}_{2} \mathrm{C}$ & $207.0 \pm 62.3$ \\
$\mathrm{Y}_{2} \mathrm{O}_{3} \mathrm{C}$ & $271.1 \pm 6.4$ \\
\hline
\end{tabular}

as the Hamaker constant, the true density, the particle size distribution and the particles' rugosity. It is then of great interest to investigate the ranking of these different input factors according to their relative influence on the Bond number variability. Indeed, such a study would allow to identify which particle properties have the most significant impact on the population dependent granular Bond number calculated, and therefore on the powder flow behavior, according to relation (6).

The sensitivity analysis of a model consist in investigating how the variation of the output of the model can be attributed to the variations of the input factors. In particular, it can be used in order to identify the parameters that might have a significant, or negligible, influence on the output variability (Pianosi et al., 2016). Applied to this study, it allows assessing which particle properties are the most critical on the powder macroscopic flow behavior. In this section, we provide a brief local sensitivity analysis, meaning that the variations of the input factors are investigated around a specific value, and not all the space of variability. A "one-at-atime" (OAT) perturbation and derivative method is used for its simplicity (Norton, 2015). Even if this method provides relevant information as a first approach, it should be noted that it does not take into account the interactions between input factors and considers local sensitivity only.

The granular Bond number, as defined by Eqs. (5) and (15), depends on four physical particle properties: the true density $\rho_{s}$, the Hamaker constant $A$, the particle asperity size $d_{a s p}$ and the particle size distribution. Among these input properties, the particle size is a distributed parameter, while the other three properties are non-distributed. Rigorously, the surface energy and the particles' rugosity should be distributed as well as they might depend on the size of the particles. However, much further characterizations would be needed in order to take these specifications into account, making the model much more difficult to use for quick predictions. In a first step, an analysis is carried out considering only non-distributed properties. Then, in a second step, the particle size distribution is considered.

\subsubsection{Non-distributed properties}

As a first approach, we will consider that the particle size can be represented by the Sauter mean diameter $D_{s}$, as it was already done in previous studies (Capece et al., 2015). The mean granular

Bond number $\overline{B o}_{G}$ of a mono-constituent powder can then be defined, using Eq. (16), as a continuous function, depending on four non-distributed variables: $\overline{B o}_{G}=f\left(A, \rho_{s}, D_{s}, d_{a s p}\right)$.

$\overline{B o_{G}}=\frac{A}{6 \pi g \rho_{s} z_{0}^{2}} \times \frac{1}{D_{s}^{2}}\left(\frac{1}{2\left(1+\frac{d_{a s p}}{2 z_{0}}\right)^{2}}+\frac{3 d_{a s p}}{d_{a s p}+D_{s}}\right)$

The sensitivity of the mean granular Bond number according to each parameter is investigated by analyzing the variation induced by a perturbation, one at a time, of each individual parameter (Pianosi et al., 2016). For example, The variation induced by a perturbation of the true density $\Delta \rho_{s}$ can be expressed as:

$\Delta_{\rho_{s}} \overline{B o_{G}}=\frac{\overline{B o_{G}}\left(\rho_{s}, A, D_{s}, d_{a s p}\right)-\overline{B o_{G}}\left[\left(\rho_{s}+\Delta \rho_{s}\right), A, D_{s}, d_{a s p}\right]}{\overline{B o_{G}}\left(\rho_{s}, A, D_{s}, d_{a s p}\right)}$

Then, the normalized sensitivity factor of first order, $s_{\rho_{s}}$ related to the true density is defined as the ratio between the variation induced by the perturbation and the initial perturbation itself as shown by Eq. (18). Thus, a sensitivity factor $s_{\chi}=1$ means that a perturbation on the parameter $\chi$ will produce a perturbation of the same magnitude on the mean granular Bond number. Likewise, a sensitivity factor $s_{\chi} \gg 1$ means that the mean granular Bond number is highly sensitive to the parameter $\chi$.

$s_{\rho_{s}}=\left|\frac{\Delta_{\rho_{s}} \overline{B o}}{\Delta \rho_{s}}\right|$

The sensitivity factors of each parameter were computed for perturbations in a range of $-20 \%$ to $+20 \%$ around a nominal value. The measured properties of the $\mathrm{Al}_{2} \mathrm{O}_{3} \mathrm{G}$ powder are chosen as the nominal values because this powder exhibits an intermediate flow 
behavior and granular Bond number compared to the other powders investigated $\left(\rho_{s}=4.107 \mathrm{~g} . \mathrm{cm}^{-3}, A=1.57 * 10^{-19} \mathrm{~J}, D_{s}=23.1 \mu \mathrm{m}\right.$ and $d_{a s p}=200 \mathrm{~nm}$ ). Fig. 7 shows the sensitivity factors obtained for each parameter and for different initial perturbations. The results indicate that the sensitivity factor corresponding to the Sauter mean diameter is significantly higher compared to those related to other parameters. Besides, the sensitivity factors related to the true density and the Hamaker constant appears to be equal to one. This is perfectly consistent with Eq. (16) in which the mean granular Bond number appears to be proportional to the Hamaker constant, and inversely proportional to the true density. Finally, the sensitivity parameter of the particle asperity size is also close to one, assuming that its value is around $200 \mathrm{~nm}$.

The sensitivity analysis of non-distributed parameters shows that all the particles properties considered in this paper have significant influence on the value of the mean granular Bond number computed. However, among these properties, the particle size is the most critical one. According to relation (6), this means that particles' size, density, surface energy and rugosity have an effect on the macroscopic flow behavior of the powders, but particle size seems to be of first importance. This result is perfectly consistent with most experimental studies reported in the literature (Fu et al., 2012; Tomas, 2001; Yu et al., 2011).

\subsubsection{Distributed properties}

Previous section showed that the size of the particles is the most important particle parameter regarding the mean granular Bond number. However, the population dependent granular Bond number uses the whole size distribution instead of the Sauter mean diameter. In order to investigate the influence of the particle size distribution on the population dependent granular Bond number, different volume particle distributions $F_{R R}(x)$ were artificially created using the Rosin-Rammler law, given by Eq. (19). This law, commonly used for distribution simulation (Vesilind, 1980), uses two parameters: $x_{0}$ which is the location parameter of the distribution, and $n$ which is the spread parameter. A high value of $n$ corresponds to a narrow distribution.

$F_{R R}(x)=1-e^{-\left(\frac{x}{x_{0}}\right)^{n}}$

Eleven artificial particle size distributions were made up and the population dependent granular Bond number was computed for each distribution using the $\mathrm{Al}_{2} \mathrm{O}_{3} \mathrm{G}$ powder properties $\left(\rho_{s}=4.107 \mathrm{~g} . \mathrm{cm}^{-3}, \quad A=1.57 * 10^{-19} \mathrm{~J}, \quad d_{\text {asp }}=200 \mathrm{~nm} \quad\right.$ and $\left.z_{0}=0.4 \mathrm{~nm}\right)$. However, the same results were obtained using the properties of the other powders investigated in this study. The spread and location parameters of the distributions are shown in Table 6. These parameters were chosen in order to obtain distributions in the same range than those corresponding to the real powders, given on Fig. 4. Table 6 shows also the population dependent granular Bond number computed from these distributions. The decile $\left(d_{10}, d_{50}\right)$, the Sauter mean diameter $D_{s}$ and the span parameter of the distributions were also calculated and are given in the same Table 6. Distributions AA1 and AA2 are created from a linear combination of two Rosin-Rammler distributions in order to obtain bimodal distributions.

The curves corresponding to the distributions of Table 6 are shown on Fig. 8. Distributions A1, A2, A3 and A4 share the same location parameter $x_{0}=55 \mu \mathrm{m}$ but have different spread parameters $n$ (Fig. 8 (a)). Whereas distributions A2, A5 A6 and A7 share the same spread parameter $n=3.0$ with different location parameters (Fig. 8 (b)). Finally, distributions A3, A8, AA1 and AA2 almost share the same median diameter $d_{50}$ around $32.5 \mu \mathrm{m}$, but have different span parameters (Fig. 8 (c)). In that case, the distributions $\mathrm{AA} 1$ and $\mathrm{AA} 2$ are bimodal, while $\mathrm{A} 3$ and $\mathrm{A} 8$ are monomodal. In particular, one can notice that A8 and AA1 have the same median diameter and almost the same span parameter but with different modalities (bimodal or monomodal). The median diameter and the span are used instead of $x_{0}$ and $n$ for these distributions because AA1 and AA2 are not Rosin-Rammler type distributions.

The population dependent granular Bond number corresponding to each distribution of Table 6 were computed using the $\mathrm{Al}_{2} \mathrm{O}_{3} \mathrm{G}$ powder properties. The values obtained are plotted against the spread parameter $n$, the location parameter $x_{0}$, the span and the median diameter $d_{50}$ on Fig. 9 (a), (b), (c) and (d) respectively.

Fig. 9 (a) shows that, for a given location parameter, the Bond number becomes smaller when the spread parameter is higher. This result implies that the cohesive forces become less important when the distribution is narrower. However, Fig. 9 (a) also shows that two distributions sharing the same spread parameter can demonstrate very different Bond numbers depending on their location parameter (A5 and A7 for example). Fig. 9 (b) represents the population dependent granular Bond number as a function of the Rosin-Rammler location parameter $x_{0}$. For a given spread parameter ( $n=3.0$ for this example), the Bond number decreases when the position parameter increases. Indeed, the cohesion forces are

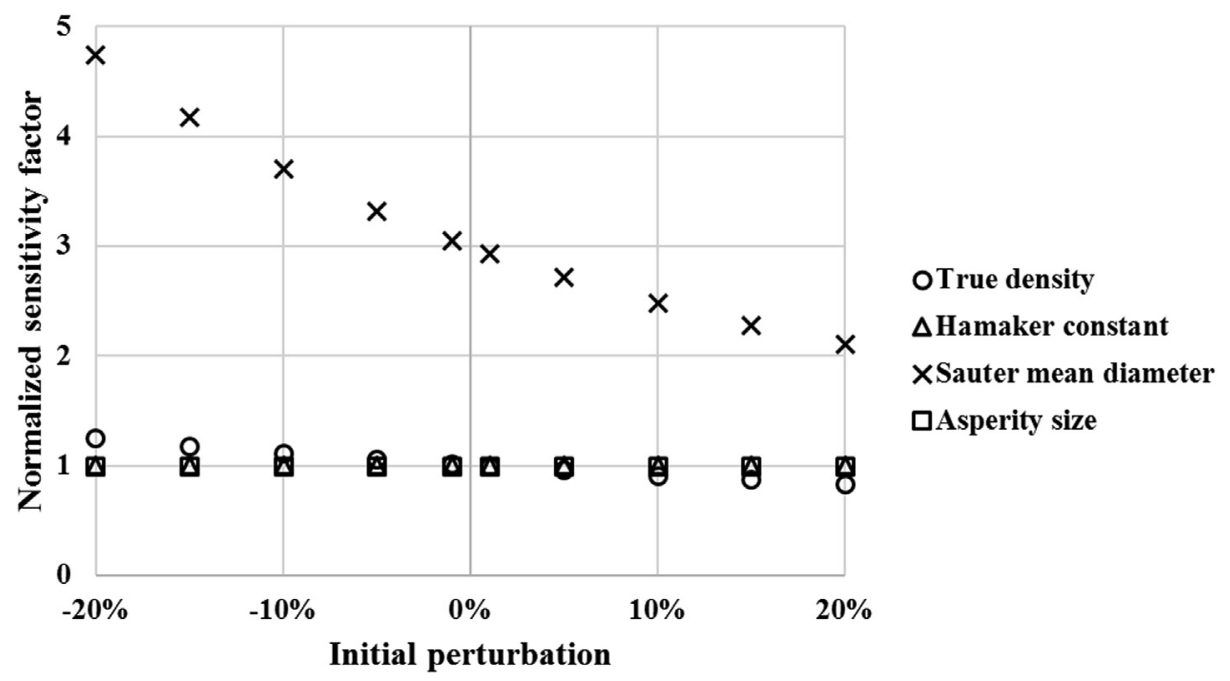

Fig. 7. Sensitivity factors of the mean granular Bond number according to different parameters, for initial perturbations in a rango of $-20 \%$ to $+20 \%$. 
Table 6

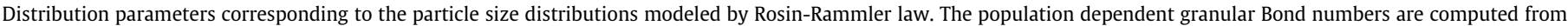
the distributions using the $\mathrm{Al}_{2} \mathrm{O}_{3} \mathrm{G}$ powder properties

\begin{tabular}{|c|c|c|c|c|c|c|c|}
\hline Name & $x_{0}(\mu \mathrm{m})$ & $n$ & $d_{10}(\mu \mathrm{m})$ & $d_{50}(\mu \mathrm{m})$ & $D_{S}(\mu \mathrm{m})$ & span & $B o_{g}$ \\
\hline $\mathrm{A} 1$ & 55 & 4.0 & 23.6 & 42.4 & 38.4 & 0.9 & $3.56 \times 10^{1}$ \\
\hline A2 & 55 & 3.0 & 15.7 & 37.3 & 28.7 & 1.2 & $7.19 \times 10^{1}$ \\
\hline A3 & 55 & 2.5 & 10.4 & 32.6 & 19.8 & 1.6 & $1.71 \times 10^{2}$ \\
\hline A4 & 55 & 1.9 & 3.6 & 22.5 & 5.0 & 2.5 & $3.52 \times 10^{3}$ \\
\hline A5 & 90 & 3.0 & 25.7 & 61.1 & 46.9 & 1.2 & $1.66 \times 10^{1}$ \\
\hline A6 & 20 & 3.0 & 5.7 & 13.6 & 10.4 & 1.2 & $1.48 \times 10^{4}$ \\
\hline A7 & 5 & 3.0 & 1.4 & 3.40 & 2.6 & 1.2 & $9.08 \times 10^{4}$ \\
\hline A8 & 90 & 1.8 & 4.2 & 32.7 & 5.0 & 2.8 & $2.33 \times 10^{3}$ \\
\hline A9 & 89 & 3.0 & 25.4 & 60.4 & 46.6 & 1.2 & $1.71 \times 10^{1}$ \\
\hline AA1 & $A 6+5 * A 5$ & & 11.6 & 32.6 & 25.4 & 2.7 & $8.15 \times 10^{1}$ \\
\hline AA2 & $\mathrm{A} 7+20^{*} \mathrm{~A} 9$ & & 2.9 & 32.4 & 7.5 & 3.0 & $1.28 \times 10^{3}$ \\
\hline
\end{tabular}

(a).

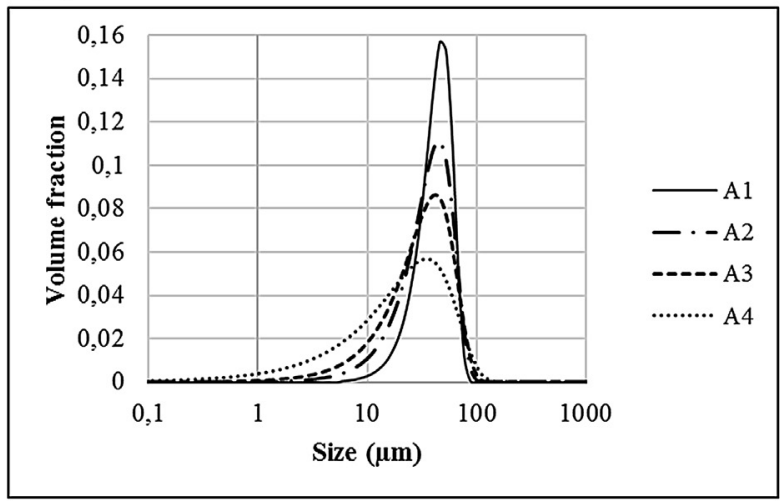

(c).

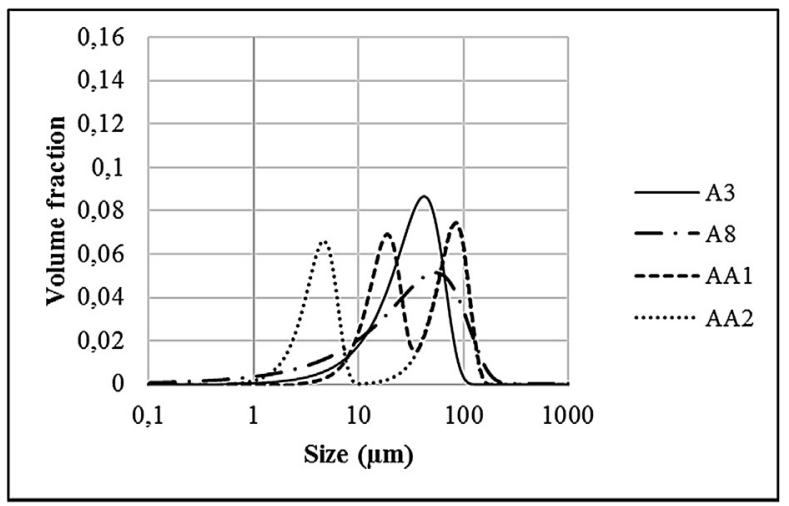

(b).

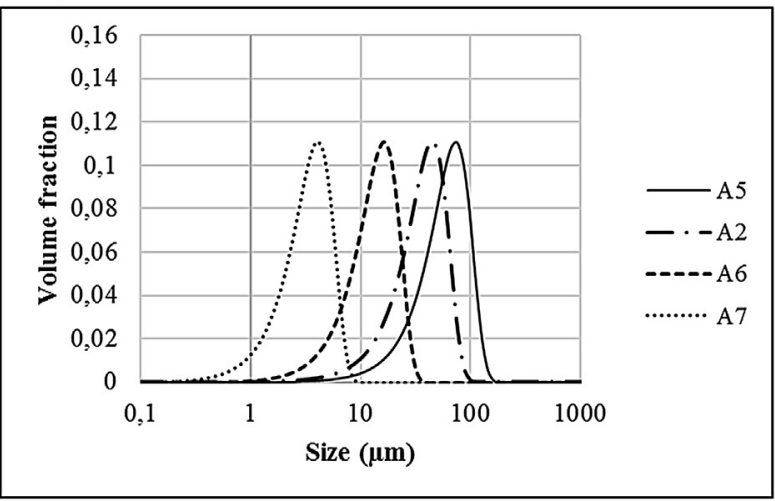

Fig. 8. Size distributions of Table 6, simulated through the Rosin-Rammler equation.

expected to become less influent than the weight of the particles as their size increases. However, it also appears that two distributions having the same location parameter can show significantly different Bond number depending on their spread parameter. Fig. 9 (a) and (b) show that both location and spread of the distributions have an influence on the population dependent granular Bond number.

Fig. 9 (c) and (d) show the evolution of the population dependent granular Bond numbers according to the span parameter and to the median diameter $d_{50}$ of the distributions, respectively. The span and the median diameter are used instead of the RosinRammler parameters in order to include the bimodal distributions AA1 and AA2 that cannot be described using two simple RosinRammler parameters. The observations made on Fig. 9 (a) and (b) also applies to Fig. 9 (c) and (d): the Bond number seems to be higher for more disperse and smaller particle sizes, but both parameters seem to be interdependent. We can also note on Fig. 9 (c) that distributions AA1 (bimodal) and A8 (monomodal) have very different Bond numbers despite the fact that they almost share the same span and median diameters. This suggests that the span and the median diameter might not be the most relevant parameters to assess the population dependent granular Bond number, especially for polydispersed powders. However, we can notice a global trend on Fig. 9 (d) suggesting that the Bond number decreases with the median diameter even if there is still significant differences between some distributions having different spreads.

Considering that the Bond number is correlated to the flowability, Fig. 9 suggests that the flowability increases when the distribution becomes narrower and when the mean particle diameter increases. This is consistent with many theoretical and experimental studies found in the literature (Fu et al., 2012). However, it is not possible to assess which is the most influent parameter among 
(a).

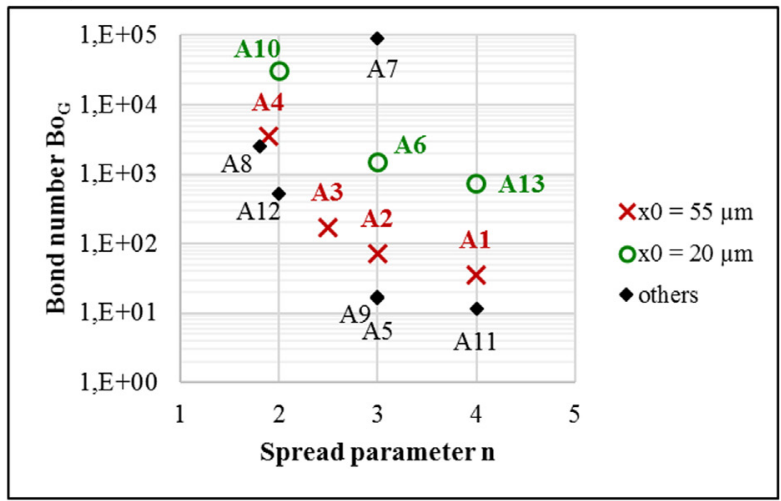

(c).

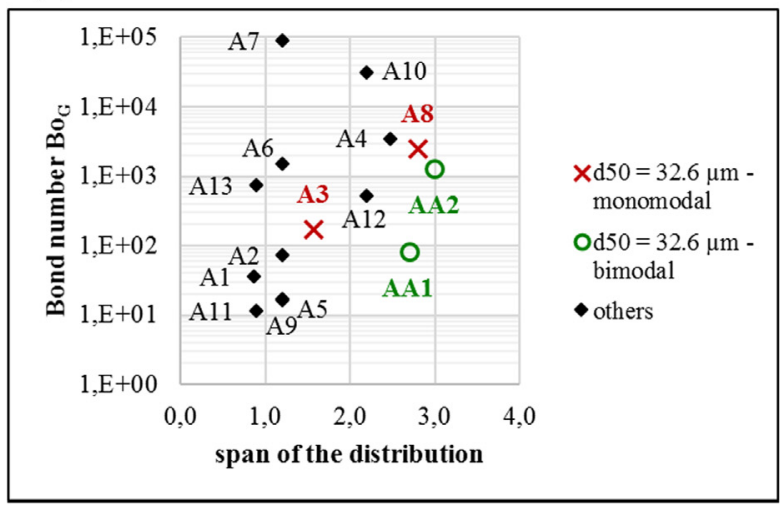

(b).

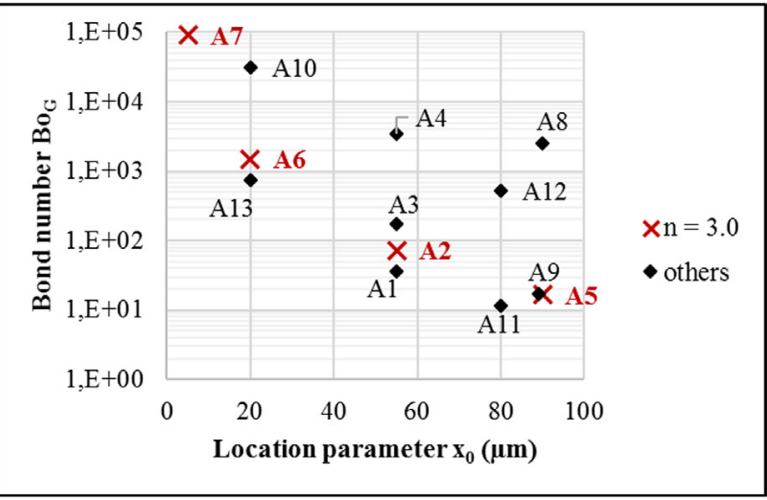

(d).

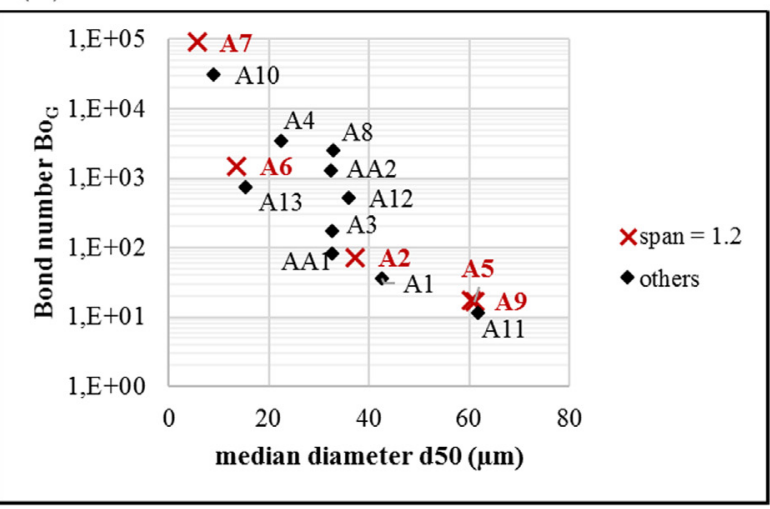

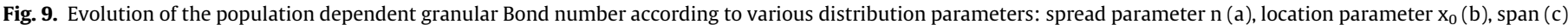
and median diameter $\mathrm{d}_{50}(\mathrm{~d})$.

the location and the spread of the distribution from this data. One possible explanation for these results is that the finest particles of the distribution are the most influent on the computed Bond number. Indeed, the amount of fine particles within a given distribution depends simultaneously on its location and its spread: it increases when the location parameters, $x_{0}$ and $d_{50}$ decrease and when the distribution becomes more disperse ( $n$ decreases and span increases). This would be consistent with Hamaker's theory suggesting that the Van der Waals force applied to two particles in interaction is dominated by the size of the smallest particle (Hamaker, 1937). Applied to a polydispersed mixture, that would imply that the flowability of the whole powder is mostly controlled by the contribution of the finest particles.

3.1.3. Links between the population dependent granular Bond number and some characteristic distribution parameters

Previous section 3.1.2 showed that the Rosin-Rammler parameters, the span or the median diameter were not sufficient to explain the value of the population dependent granular Bond number. However, Fig. 10 show that the population dependent granular Bond number seems to be closely correlated to the first decile $d_{10}$ and the Sauter mean diameter $D_{s}$, whatever the other characteristics of the distributions (spread, modality etc.). The dotted lines of Fig. 10 corresponds to power law interpolations. The equations and determination coefficients corresponding to these power laws are given in Table 7. The fact that the population dependent granular Bond number seems to be correlated to those two parameters can be explained physically:
The first decile diameter is characteristic of the finest particles among a given particle size distribution. As discussed in the previous paragraph, according to the Hamaker's theory, these fine particles are expected to be the more influent on the overall cohesion of the powder.

- The Sauter mean diameter takes into account the ratio between the surface and the volume of the particles. Yet, the Van der Waals force and the weight applies respectively on the surface and for the volume of the particles. Then it is not surprising to find that the Bond number, defined as the ratio between Van der Waals force and weight, appears correlated to the Sauter mean diameter.

As a conclusion for this section, the population dependent granular Bond number, as defined in sections 1 and 2.3.2, depends on four physical properties of the particles constituting a powder medium: the true density, the Hamaker constant, the particle asperity size and the particle size distribution. Although the population dependent granular Bond number is sensitive to each of these parameters, the particle size distribution seems to be the most influent one. It also appears that the fraction of fine particles and the Sauter mean diameter are closely correlated to the population dependent granular Bond number, whatever the shape and the spread of the distribution. In particular, the population dependent granular Bond number seems to be proportional to the Sauter mean diameter at the power -2.6 , as shown by Eq. (20):

$B o_{G} \propto D_{S}^{-2.6}$ 


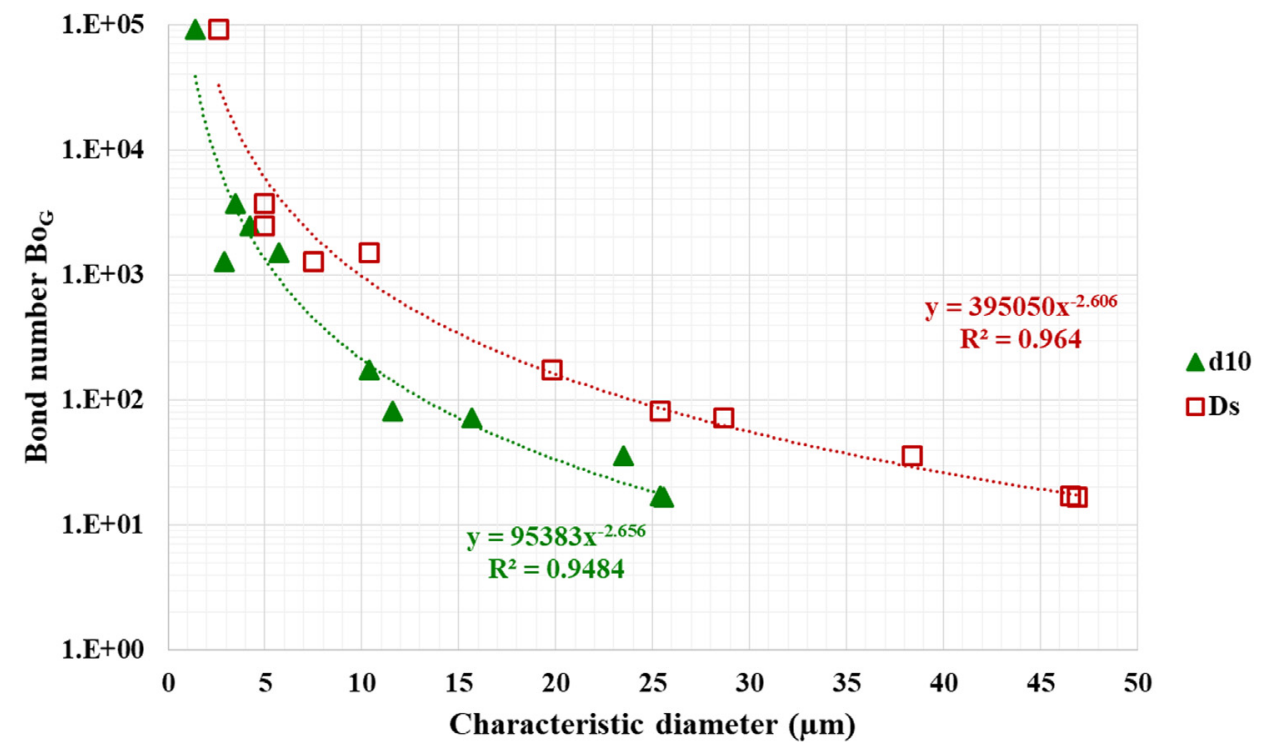

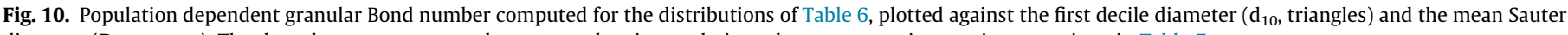
diameter $\left(D_{s}\right.$, squares). The dotted curves corresponds to power law interpolations those parametric equations are given in Table 7.

Table 7

Parametric equations and regression coefficients corresponding to the powder law interpolations of Fig. 10.

\begin{tabular}{llll}
\hline Correlation & $\begin{array}{l}\text { Correlation } \\
\text { type }\end{array}$ & Parametric equation & $\begin{array}{l}\text { Determination } \\
\text { coefficient }\end{array}$ \\
\hline$B o_{G}=f\left(d_{10}\right)$ & Power law & $B o_{g}=9.5 \times 10^{4} \times d_{10}{ }^{-2.7}$ & $R^{2}=0.9484$ \\
$B o_{G}=f\left(D_{S}\right)$ & Power law & $B o_{g}=3.9 \times 10^{5} \times D_{S}{ }^{-2.6}$ & $R^{2}=0.9640$ \\
\hline
\end{tabular}

\subsection{Relationship with Rumpf's theory}

Equation (21), known as the theoretical Rumpf's equation, is widely used to express the link between the tensile strength $\sigma_{z}$ of a powder bed, the particles properties and the powder bed structure (Molerus, 1975; Tsubaki, 1984):

$\sigma_{z}=\frac{\kappa}{\pi}(1-\varepsilon) \frac{F_{v d W}}{d^{2}}$

Here $\kappa$ is the powder bed coordination number, $\varepsilon$ is the powder bed porosity and $d$ is the particle diameter. As the cohesion $c$ of a powder bed is easily measurable, it is often used instead of the tensile strength (Tomasetta et al., 2014) and Eq. (21) becomes Eq. (22), neglecting the effect of the friction coefficient which is approximately the same for all the powders investigated.

$c \frac{\kappa}{\pi}(1-\varepsilon) \frac{F_{v d W}}{d^{2}}$

It is then possible to express the relationship between the granular Bond number and the cohesion between two particles by combining Eqs. (1) and (22):

$c=f(\varepsilon, \kappa) \frac{W \times B o_{G}}{d^{2}}$

where $f(\varepsilon, \kappa)$ is a function that depends only on the powder bed structure. In addition $W$ represents the weight of the particles in contact at the failure plane. It can be estimated as the geometric mean of both particles in interaction at the failure plane, as in Eq. (4), and is proportional to the particle diameter cubed. Equation (23) then becomes Eq. (24) where $a$ depends on the powder bed structure and on the true density of the particles. $c=a\left(\varepsilon, \kappa, \rho_{s}\right) \times d \times B o_{G}$

Besides, it was shown in the previous section 3.1.3 (Table 7) that the population dependent granular Bond number is approximately proportional to the particle diameter at the power -2.6 , if we assume that the Sauter mean diameter is a correct approximation of the particles size, we can get Eq. (25):

$c=a\left(\varepsilon, \kappa, \rho_{s}\right) \times B o_{G}^{b}$

Where the exponent $b=-\frac{1}{2.6}+1=0.6$ comes from the combination of Eqs. (20) and (24).

Finally, we can combine Eqs. (10) and (25) to get a relationship between the flow index $f f_{c}$ and the population dependent granular Bond number of a given powder according to the Rumpf's theory:

$f f_{c}=\alpha\left(\varepsilon, \kappa, \rho_{s}\right) \times B o_{G}{ }^{-\beta}$ with $\beta=0.54$

where $\alpha$ is a proportionality factor that depends on the powder bed structure and on the true density of the particles, derived from $a$ and Eq. (10), and given by expression (27):

$\alpha\left(\varepsilon, \kappa, \rho_{s}\right) \approx 4.664 \times a\left(\varepsilon, \kappa, \rho_{s}\right)^{-0.90}$

Then, according to the Rumpf's theory, the flow index of a powder bed, measured using a powder rheometer under a $9 \mathrm{kPa}$ preconsolidation stress is expected to be roughly inversely proportional to the square root of the population dependent granular Bond number, and also to depend on the powder bed structure and true density.

Equation (26) is derived from Rumpf's theory represented by Eq. (21), the analysis of the population dependent granular Bond number (Eq. (20)) and the powder flowability measurements carried out with an $\mathrm{FT} 4{ }^{\circledR}$ powder rheometer (10). It is a semiempirical model that correlates the macroscopic flow behavior of the powder to the microscopic particles properties. Indeed, the flow index is a characteristic of the powder flow behavior and the population dependent granular Bond number is representative of the interparticle forces at particle scale. This semi-empirical correlation between macroscale powder behavior and microscale particle properties has been tested experimentally, the results are given in next section 4 . 


\section{Experimental results and discussion}

\subsection{Experimental results}

On Figure 11, the flow index measured by shear tests in a powder rheometer, is plotted as a function of the population dependent granular Bond number (on a logarithmic scale) that has been computed from particles characterizations summarized in Table 4. Only the flow indexes in dry conditions Table 2 are kept since some powders might exhibit capillary forces, due to relative humidity sensitivity, which is not taken into account for the interparticle forces calculation in Eq. (1).

The cross symbols represents the experimental results for each powder and the error bars correspond to their standard deviations. The $\mathrm{ZrO}_{2} \mathrm{G}$ powder does not appear on the figure since its flow index could not be computed as explained in section 2.2.1. In virtue of Eq. (26), the flow index is expected to vary with the population dependent granular Bond number according to a power law with an exponent $\beta$ of 0.54 , and the proportionality factor $\alpha$ should depend on the state of consolidation of the powder and its true density. Since all the powders investigated have a similar true density (between 4 and $6 \mathrm{~g} . \mathrm{cm}^{-3}$, according to Table 4), and since they are approximately in the same state of consolidation during the shear tests (same pre-consolidation stress set to $9 \mathrm{kPa}$ ), we can assume that the proportionality $\alpha$ is constant for the powders investigated.

The dotted line corresponds to the power law fit given by Eq. (28), which has the same form than Eq. (26), where the exponent $\beta$ is fixed at 0.54 according Rumpf's theory and Eqs. (10) and (20). The proportionality factor $\alpha$ is adjusted with the least square method in order to fit the experimental data. A value of $\alpha=89.5$ was found with a total squared error of $S^{2}=3.5670$ between the experimental data and the power law equation.

$f f_{c}=\alpha \times B o_{G}{ }^{-\beta}$ with $\left\{\begin{array}{l}\alpha=89.5 \\ \beta=0.54\end{array}\right.$

It appears on Figure 11 that the flow index of these powders is correlated to the population dependent granular Bond number and that this correlation is consistent with Eq. (26), derived from the Rumpf theory. The correlation (28) is of great interest for understanding the relationship between macroscopic flow behavior of powders and the microscopic scale properties of the particles constituting the powder bed. It suggests that the flow index is approximately inversely proportional to the square root of the population dependent granular Bond number, which is itself mostly dependent on the particle size distribution, and in particular, on the fraction of fine particles. The correlation then confirms that the fraction of fine particles among a powder bed is a critical parameter that has a great influence on the its flowability, which is consistent with many experimental results (Liu et al., 2008; Vlachos and Chang, 2011).

\subsection{Discussion and comparison with the literature}

The correlation represented by Eq. (28) can be compared to similar correlations obtained experimentally by other authors. The values for parameters $\alpha$ and $\beta$ found in the literature are given in Table 8 . Despite the fact that all these studies found a power law correlation, the equation parameters $\alpha$ and $\beta$ vary significantly between the authors and are not the same than those suggested in this paper. However, these variations can be explained from the various conditions of flow index measurements and Bond number calculation method. The most relevant differences are listed in Table 8 and are explained in next paragraphs.

First, it should be noted that Eq. (26) comes from a combination of Eq. (25), derived from Rumpf's theory and Eq. (10), which is empirical and might be valid only for the powders and the equipment used for a given investigation protocol. It follows that, rigorously, the correlation parameters $\alpha$ and $\beta$ found in this study should not be compared directly with those obtained in the literature. Actually, the correlation that comes from the Rumpf's equation is Eq. (25) which gives the link between the cohesion of the powder and the population dependent granular Bond number.

Moreover, some studies were carried using pharmaceutical powders with true densities in a range of 1 to $3 \mathrm{~g} . \mathrm{cm}^{-3}$. While other studies, including this one, used ceramic powders with true densities from 4 to $6 \mathrm{~g} . \mathrm{cm}^{-3}$. According to section 3.2, the proportionality factor $\alpha$ is expected to vary when the true densities of the powder becomes too different. This could partially explain the significant difference between the $\alpha$ parameters fond with ceramic and pharmaceutical powders. However, section 3.2 also suggests that the proportionality factor $\alpha$ is affected by the state of consolidation of the powder bed as well. Meaning that different shear testing procedure may provide different results on Eq. (28) parameters. The differences between Shulze RTS-XS ${ }^{\circledR}$ and Freeman FT4 ${ }^{\circledR}$

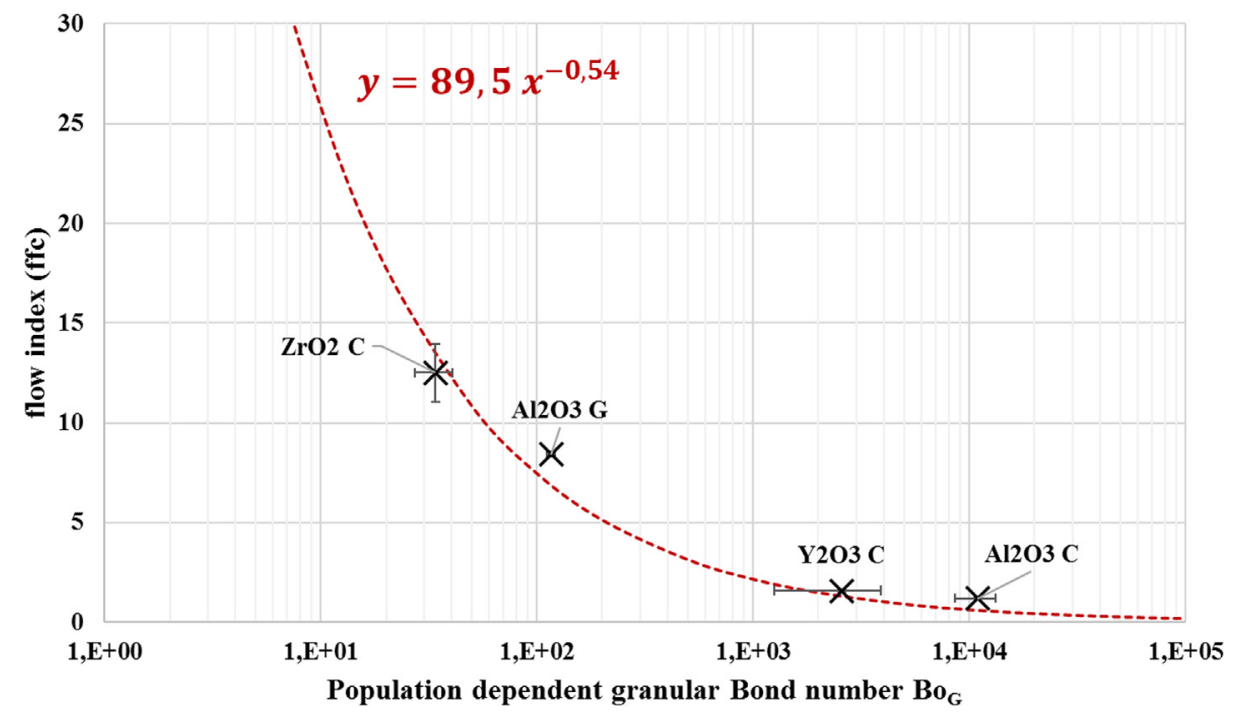

Fig. 11. Flow index of the powders plotted as a function of their population dependent granular Bond number. 
Table 8

Other correlations found in the literature

\begin{tabular}{|c|c|c|c|c|c|}
\hline Reference & Power law parameters & Powders used & Shear test device & Type of Bond number & Van der Waals force model \\
\hline This study & $\alpha=89.5 \beta=0.54$ & Oxide powders & Freeman FT4 ${ }^{\circledR}$ & Population dependent & Rumpf modified (3) \\
\hline (Capece et al., 2015) & $\alpha=15.7 \beta=0.27$ & Pharmaceutical powders & Shulze RST-XS ${ }^{\circledR}$ & Mean & Rumpf modified ( 3 ) \\
\hline (Capece et al., 2016) & $\alpha=14.8 \beta=0.28$ & Pharmaceutical powders & Shulze RST-XS ${ }^{\circledR}$ & Population dependent & Rumpf modified (3) \\
\hline (Bernard-Granger et al., 2019) & $\alpha=204 \beta=0.29$ & Oxide powders & Freeman FT4 ${ }^{\circledR}$ & Mean & Hamaker (2) \\
\hline
\end{tabular}

rheometers is well documented in the literature (Koynov et al., 2015). Even if they follow a similar measurement protocol, they cannot perform shear tests in the same state of consolidation. Indeed, Capece's measurements were carried out with an annular cell under a pre-consolidation stress of $300 \mathrm{~Pa}$, while the measurements carried out for our investigation were performed with a cylindrical cell under a pre-consolidation stress of $9 \mathrm{kPa}$. In particular, it was shown in the literature that the pre-consolidation stress affects significantly the powder bed porosity and the macroscopic flow behavior of the powder (Legoix et al., 2017). Thus, the proportionality factors $\alpha$ obtained may vary when the flow index is measured with a different device or under a different preconsolidation stress.

In order to study in more detail the influence of the powder bed structure on the correlation's parameters, several shear tests were performed on the same powders with a FT $4{ }^{\circledR}$ rheometer under different consolidations stresses. Since the relationship between the flow index and the cohesion parameter (Eq. (10)) may vary with the pre-consolidation stress, Eq. (25), involving the cohesion, is used instead of Eq. (26) in order to check the consistency with Rumpf's theory. Table 9 gives the cohesion parameters obtained for each powder under 3, 6, 9 and $15 \mathrm{kPa}$ pre-consolidation stresses. The incertitudes given in Table 9 correspond to the standard deviations between two samples; they only appear on $9 \mathrm{kPa}$ measurements since other pre-consolidations values were tested only once for each powder. It appears that the cohesion measured for each powder is significantly higher when the pre-consolidation stress increases. This result is in good agreement with the literature (Legoix et al., 2017) and can be explained by the fact that the powder is expected to be more resistive to the flowability when it has been consolidated under a higher normal stress. The cohesion obtained for each powder and for each preconsolidation stress is plotted against the population dependent granular Bond number on Figure 12. The assumption that the population dependent granular Bond number is not a function of the powder bed structure is reasonable since it only depends on individual particle properties. The error bars corresponds to the standard deviations of the measurements. The dotted lines on Figure 12 corresponds to the power law Eq. (25) where the exponent is fixed to 0.6 , according to Rumpf's theory and the proportionality factor $a$ is adjusted using the least square method in order to fit the data. The values obtained for the proportionality factors for each pre-consolidation stress are given on Table 10 with the corresponding total squared error. The results show that the proportionality factor $a$ varies with the pre-consolidation stress. That means that $a$ is a function of the powder bed structure, as expected in Eq. (25). More precisely, $a$ increases when the powder bed is more compacted. Since a high cohesion value leads to a low flow index, the proportionality factor $\alpha$ is then expected to decrease when the pre-consolidation stress becomes higher. This could explain why the $\alpha$ parameters obtained with a preconsolidation stress of $300 \mathrm{~Pa}$ (Capece et al., 2016, 2015) are considerably lower than those obtained in this study (Table 8) or other studies using a $9 \mathrm{kPa}$ pre-consolidation stress (Bernard-Granger et al., 2019).

Finally, we can notice that the correlations obtained in this study and by Bernard-Granger (Bernard-Granger et al., 2019) still differs significantly despite the fact that the same powders and the same measurement protocol were used. However, these differences are explained by the fact that the granular Bond number computed by Bernard-Granger does not take into account the whole particle size distribution and only considers smooth particles $\left(d_{\text {asp }}=0 \mu \mathrm{m}\right)$. Thus, the granular Bond number is probably less accurate since alumina powders, especially the $\mathrm{Al}_{2} \mathrm{O}_{2} \mathrm{C}$ powder, exhibit a sparse particle size distribution and is characterized by rough particles. This underlines the importance of the population dependent granular Bond number when dealing with polydispersed powders. Moreover, the particle diameter used for the granular Bond number calculation by (Bernard-Granger et al., 2019) is the diameter given by the powder manufacturer, but does not corresponds to the measurements carried out by either LASER granulometry or SEM picture analysis (Bernard-Granger et al., 2019). This probably leads to a lesser accurate granular Bond number value. Deeper powder characterizations were carried out for this study, leading to more exact granular Bond number and flow index values.

As a conclusion for this section, the proportionality factors $a$ and $\alpha$ of Eqs. (25) and (26) respectively, are material dependent and may also vary with the flow measurement technique. On the other hand, the exponent $b=0.6$ of Eq. (25) is derived from Rumpf's theory and is expected to be material independent. However, the exponent $\beta$ is derived not only from Rumpf's theory but also from empirical equation (10). Thereby, caution should be taken when comparing $\alpha$ and $\beta$ parameters obtained for different studies.

\section{Conclusion and perspectives}

This paper confirms and develops the correlation found in previous investigations regarding the relationship between the macroscopic flow behavior of a powder and the microscopic properties of the particles constituting the powder bed, represented by the population dependent granular Bond number. The power law

Table 9

Cohesion of the powders measured with a FT $4{ }^{\circledR}$ powder rheometer under different pre-consolidations stresses

\begin{tabular}{|c|c|c|c|c|}
\hline \multirow[t]{2}{*}{ Powder } & \multicolumn{4}{|l|}{ Cohesion $(\mathrm{kPa})$} \\
\hline & $3 \mathrm{kPa}$ pre-consolidation & $6 \mathrm{kPa}$ pre-consolidation & 9 kPa pre-consolidation & $15 \mathrm{kPa}$ pre-consolidation \\
\hline $\mathrm{Al}_{2} \mathrm{O}_{3} \mathrm{G}$ & 0.16 & 0.46 & $0.54 \pm 0.01$ & 0.77 \\
\hline $\mathrm{Al}_{2} \mathrm{O}_{3} \mathrm{C}$ & 2.08 & 2.69 & $4.57 \pm 0.14$ & 5.65 \\
\hline $\mathrm{ZrO}_{2} \mathrm{G}$ & 0 & 0 & 0 & 0.09 \\
\hline $\mathrm{ZrO}_{2} \mathrm{C}$ & 0.10 & 0.24 & $0.34 \pm 0.04$ & 0.91 \\
\hline $\mathrm{Y}_{2} \mathrm{O}_{3} \mathrm{C}$ & 1.05 & 1.73 & $3.32 \pm 0.31$ & 3.95 \\
\hline
\end{tabular}




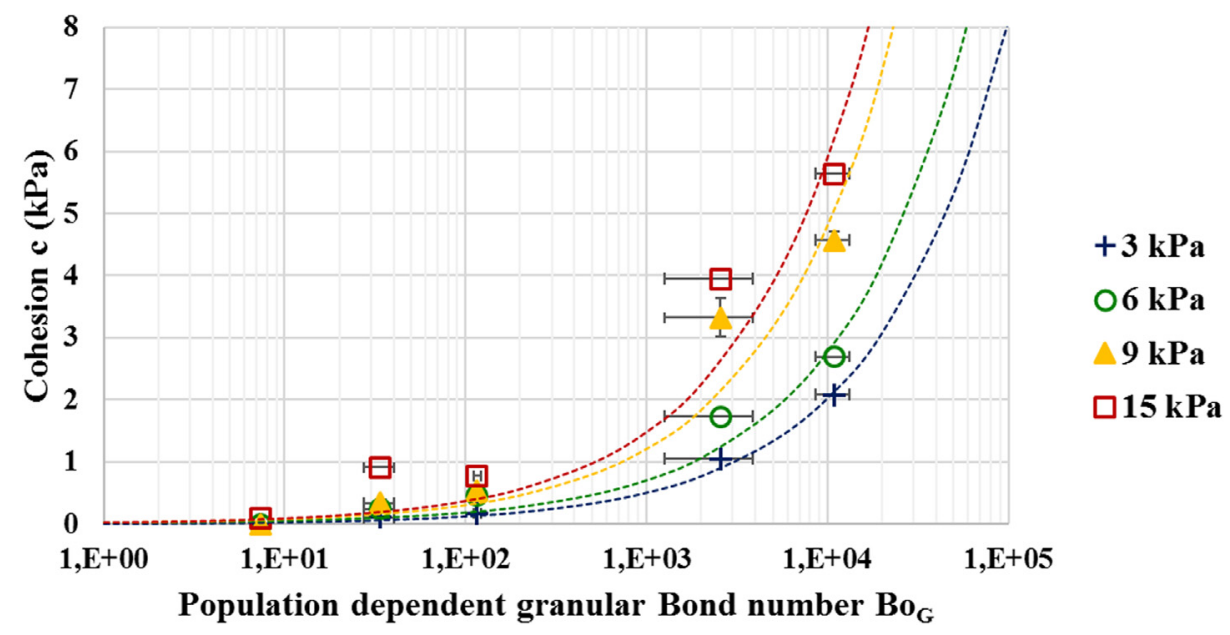

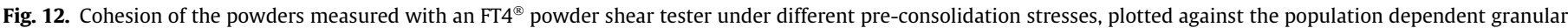
Bond number. The dotted lines correspond to the predictions of equation Eq. (25) according to Rumpf's theory.

Table 10

Proportionality factors and total squared error corresponding to the correlations of Fig. 12

\begin{tabular}{|c|c|c|c|c|}
\hline Pre-consolidation stress $\sigma_{c}(\mathrm{kPa})$ & 3 & 6 & 9 & 15 \\
\hline Proportionality factor $a(\mathrm{kPa})$ & 0.008 & 0.011 & 0.019 & 0.024 \\
\hline Total squared error $S^{2}$ & 0.0278 & 0.4001 & 1.7403 & 2.7640 \\
\hline
\end{tabular}

linking the flow index to the population dependent granular Bond number, introduced in previous studies (Bernard-Granger et al., 2019; Capece et al., 2016; Castellanos, 2005), was confirmed in this paper for different ceramic oxide powders. In particular, polydispersed powders exhibiting a higher true density have been investigated. Furthermore, we showed that the correlation (6), linking the flow index to the granular Bond number through a power law equation, turns out to be consistent with the Rumpf's theoretical equation. Thus, physical meanings for the power law's parameters $\alpha$ and $\beta$ were suggested. It was shown experimentally and theoretically that the proportionality factor $\alpha$ depends on the powder bed structure. It may also depend on the true density of the particles but the magnitude of this effect was not assessed experimentally since the powders used in this study have similar densities. On the other hand, the exponent $\beta$ seems to be material independent and can be found using Rumpf's theory. An effort was made in order to explain the different values of $\alpha$ and $\beta$ found in this study and among the literature. It appeared that the correlation obtained was significantly affected by the shear test measurement protocol. In particular, the pre-consolidation stress applied to the powder bed was shown to be a key parameter, as stated in previous studies (Legoix et al., 2017). The evolution of the power law parameters $\alpha$ and $\beta$ according to the preconsolidation stress has been sparsely discussed in this paper but may be studied in more detail in future work. In particular, more data should be acquired at various pre-consolidation stresses and through other rheometers.

The population dependent granular Bond number $B o_{G}$, as defined in this paper, only depends on four particles properties: true density, Hamaker constant, particle asperity size and particle size distribution. Among these parameters, the particle size distributions seems to be the most influent parameter on the population dependent granular Bond number, and thus on the flowability of the powders. In particular, the population dependent granular Bond number was shown to be strongly related to the fraction of fine particles, whatever the shape and spread of the distribution. This result suggests that the fraction of fine particles is a critical parameter that has a great influence on the flowability of the powders, which is perfectly consistent with many experimental results reported in the literature (Liu et al., 2008).

In spite of the good agreement with the empirical data, the model still has some limitations and could be improved in many aspects. In particular, the population dependent granular Bond number does not take into account the shape of the particles that are all considered spherical up to now. Finer characterization of the particle's shape distribution would be of great interest to improve the Bond number calculation. Indeed, shape factors were shown to correct efficiently the predicted interparticle forces calculation (Thomas et al., 2009). Likewise, the particles are considered as ideally distributed in the powder bed as each interaction has the same probability of occurrence in the population dependent granular Bond number calculations. However, one can expect segregation effects to occur among the particles of different size constituting a powder medium (Mayer-Laigle et al., 2015). Furthermore, it was shown that capillary forces may exist between the particles due to ambient relative humidity sensitivity. These forces, created by liquid bridges between particles in close contact, should also be taken into account in the granular Bond number calculation in order to explain the flow behavior of this powder in ambient conditions. Indeed, in presence of such forces, the effective flow index of a given powder is expected to be lower than the flow index predicted by the model neglecting capillary forces (Bernard-Granger et al., 2019). Finally, the influence of the true density of the particles on the correlation parameters are still unclear and have to be investigated experimentally using powders exhibiting a wider range of densities.

Despite these limitations, the model reveals a strong potential for predicting accurately and quickly the flowability of real polydispersed powders from simple particles properties that can be measured experimentally. Besides the prediction of a single powder flowability, the model could be applied in many industrial processes handling powders. For example, the correlation could be used to predict the flowability of multi component powder mixtures according to their formulation (Capece et al., 2016). More- 
over, it could be applied to grinding processes, giving a prediction of the flowability of the powders as their particle size decreases.

\section{Declaration of Competing Interest}

The authors declare that they have no known competing financial interests or personal relationships that could have appeared to influence the work reported in this paper.

\section{References}

Arai, Y., 1996. Chemistry of Powder Production. Particle Technology Series, Springer, Netherlands.

Aulton, M.E., 2002. Pharmaceutics : the science of dosage form design. Churchill Livingstone, Edinburgh, New York.

Bernard-Granger, G., Giraud, M., Pascal, E., Mailhan, L., Larsson, T., Valot, C., Ablitzer C., Gatumel, C., Berthiaux, H., 2019. Rheological properties of alumina powder mixtures investigated using shear tests. Powder Technol. 345, 300-310. https:/ doi.org/10.1016/j.powtec.2019.01.027.

Capece, M., Ho, R., Strong, J., Gao, P., 2015. Prediction of powder flow performance using a multi-component granular Bond number. Powder Technol. 286, 561571. https://doi.org/10.1016/j.powtec.2015.08.031.

Capece, M., Silva, K.R., Sunkara, D., Strong, J., Gao, P., 2016. On the relationship of inter-particle cohesiveness and bulk powder behavior: Flowability of pharmaceutical powders. Int. J. Pharm. 511, 178-189. https://doi.org/10.1016 j.ijpharm.2016.06.059.

Castellanos, A., 2005. The relationship between attractive interparticle forces and bulk behaviour in dry and uncharged fine powders. Adv. Phys. 54, 263-376. https://doi.org/10.1080/17461390500402657.

Chen, Y., Yang, J., Dave, R.N., Pfeffer, R., 2008. Fluidization of coated group C powders. AIChE J. 54, 104-121. https://doi.org/10.1002/aic.11368.

Cleary, P.W., 2008. The effect of particle shape on simple shear flows. Powder Technol. 179, 144-163. https://doi.org/10.1016/j.powtec.2007.06.018.

Derjaguin, B.V., Muller, V.M., Toporov, Y.P., 1975. Effect of contact deformations on the adhesion of particles. J. Colloid Interface Sci. 53, 314-326. https://doi.org/ 10.1016/0021-9797(75)90018-1.

EFCE Working Party on the Mechanics of Particulate Solids., Institution of Chemical Engineers (Great Britain), 1989. Standard shear testing technique for particulate solids using the Jenike shear cell : a report of the EFCE Working Party on the Mechanics of Particulate Solids. Institution of Chemical Engineers, Rugby, England.

Fu, X., Huck, D., Makein, L., Armstrong, B., Willen, U., Freeman, T., 2012. Effect of particle shape and size on flow properties of lactose powders. Particuology 10 , 203. https://doi.org/10.1016/j.partic.2011.11.003.

Hamaker, H.C., 1937. The London-van der Waals attraction between spherical particles. Physica 4, 1058-1072. https://doi.org/10.1016/S0031-8914(37) 80203-7.

Huang, Z., Scicolone, J.V., Gurumuthy, L., Davé, R.N., 2015. Flow and bulk density enhancements of pharmaceutical powders using a conical screen mill: A continuous dry coating device. Pharm. Part. Process. 125, 209-224. https://doi. org/10.1016/j.ces.2014.05.038.

Israelachvili, Jacob N., 2011. In: Intermolecular and Surface Forces. Elsevier, pp. 107-132. https://doi.org/10.1016/B978-0-12-375182-9.10006-5.

Israelachvili, J.N., 2011. Chapter 13 - Van der Waals Forces between Particles and. In: Surfaces, in: Intermolecular and Surface Forces. (Third Edition). Academic Press, San Diego, pp. 253-289. https://doi.org/10.1016/B978-0-12-375182 9.10013-2.

Johnson, K.L., Kendall, K., Roberts, A.D., 1971. Surface energy and the contact of elastic solids. Proc. R. Soc. Lond. Math. Phys. Sci. 324, 301-313. https://doi.org/ 10.1098/rspa.1971.0141.

Koynov, S., Glasser, B., Muzzio, F., 2015. Comparison of three rotational shear cell testers: Powder flowability and bulk density. Powder Technol. 283, 103-112. https://doi.org/10.1016/j.powtec.2015.04.027.

Legoix, L., Gatumel, C., Milhé, M., Berthiaux, H., 2017. Characterizing powders in order to determine their flow behavior in a mixer: From small scale observations to macroscopic in-mixer rheology for powders of various flowabilities. Powder Technol. 322, 314-331. https://doi.org/10.1016/j. powtec.2017.07.075.

Leturia, M., Benali, M., Lagarde, S., Ronga, I., Saleh, K., 2014. Characterization of flow properties of cohesive powders: A comparative study of traditional and new testing methods. Powder Technol. 253, 406-423. https://doi.org/10.1016/j. powtec.2013.11.045.

Levoguer, C.L., Williams, D.R., n.d. Measurement of the surface energies of pharmaceutical powders using a novel vapor adsorption method (No. Application note 17). Surface Measurement Systems Ltd, UK.

Li, Q., Rudolph, V., Weigl, B., Earl, A., 2004. Interparticle van der Waals force in powder flowability and compactibility. Int. J. Pharm. 280, 77-93. https://doi. org/10.1016/j.ijpharm.2004.05.001.

Lifschitz, E.M., Hamermesh, M., 1992. In: Perspectives in Theoretical Physics. Elsevier, pp. 329-349. https://doi.org/10.1016/B978-0-08-036364-6.50031-4.

Liu, L.X., Marziano, I., Bentham, A.C., Litster, J.D., White, E.T., Howes, T., 2008. Effect of particle properties on the flowability of ibuprofen powders. Int. J. Pharm. 362, 109-117. https://doi.org/10.1016/j.ijpharm.2008.06.023.
Mayer-Laigle, C., Gatumel, C., Berthiaux, H., 2015. Mixing dynamics for easy flowing powders in a lab scale Turbula ${ }^{\circledR}$ mixer. Chem. Eng. Res. Des. 95, 248-261. https://doi.org/10.1016/j.cherd.2014.11.003.

Molerus, O., 1975. Theory of yield of cohesive powders. Powder Technol. 12, 259275. https://doi.org/10.1016/0032-5910(75)85025-X.

Norton, J., 2015. An introduction to sensitivity assessment of simulation models. Environ. Model. Softw. 69, 166-174. https://doi.org/10.1016/j. envsoft.2015.03.020.

Pianosi, F., Beven, K., Freer, J., Hall, J.W., Rougier, J., Stephenson, D.B., Wagener, T., 2016. Sensitivity analysis of environmental models: A systematic review with practical workflow. Environ. Model. Softw. 79, 214-232. https://doi.org/ 10.1016/j.envsoft.2016.02.008.

Podczeck, F., Mia, Y., 1996. The influence of particle size and shape on the angle of internal friction and the flow factor of unlubricated and lubricated powders. Int. J. Pharm. 144, 187-194. https://doi.org/10.1016/S0378-5173(96)04755-2.

Rabinovich, Y.I., Adler, J.J., Ata, A., Singh, R.K., Moudgil, B.M., 2000. Adhesion between Nanoscale Rough Surfaces: I. Role of Asperity Geometry. J. Colloid Interface Sci. 232, 10-16. https://doi.org/10.1006/jcis.2000.7167.

Rumpf, Hans, 1990. Particle technology. Chapman and Hall, London.

Thomas, G., Ouabbas, Y., Grosseau, P., Baron, M., Chamayou, A., Galet, L., 2009. Modeling the mean interaction forces between powder particles. Application to silica gel-magnesium stearate mixtures. Appl. Surf. Sci. 255, 7500-7507. https://doi.org/10.1016/j.apsusc.2009.03.099.

Tisserand, C., Calvet, R., Patry, S., Galet, L., Dodds, J.A., 2009. Comparison of two techniques for the surface analysis of alumina (Al2O3): Inverse Gas Chromatography at Finite Concentration (IGC-FC) and Dynamic Vapor Sorption (DVS). Powder Technol. 190, 53-58. https://doi.org/10.1016/j. powtec.2008.04.058

Tomas, J., 2001. Assessment of Mechanical Properties of Cohesive Particulate Solids. Part 2: Powder Flow Criteria. Part. Sci. Technol. 19, 111-129. https://doi.org/ 10.1080/02726350152772065.

Tomasetta, I., Barletta, D., Poletto, M., 2014. Correlation of powder flow properties to interparticle interactions at ambient and high temperatures. Particuology 12, 90-99. https://doi.org/10.1016/j.partic.2013.02.002.

Tsubaki, J.-I., 1984. A review of the investigation into powder bed mechanics based on a microscopic view in Japan. KONA, 78-86.

Vesilind, P.A., 1980. The Rosin-Rammler particle size distribution. Resour. Recovery Conserv. 5, 275-277. https://doi.org/10.1016/0304-3967(80)90007-4.

Vlachos, N., Chang, I.T.H., 2011. Investigation of flow properties of metal powders from narrow particle size distribution to polydisperse mixtures through an improved Hall-flowmeter. Powder Technol. 205, 71-80. https://doi.org/ 10.1016/j.powtec.2010.08.067.

Xie, H.-Y., 1997. The role of interparticle forces in the fluidization of fine particles. Powder Technol. 94, 99-108. https://doi.org/10.1016/S0032-5910(97)03270-1.

Yu, W., Muteki, K., Zhang, L., Kim, G., 2011. Prediction of Bulk Powder Flow Performance Using Comprehensive Particle Size and Particle Shape Distributions. J. Pharm. Sci. 100, 284. https://doi.org/10.1002/jps.22254.

\section{Glossary}

Notation: Parameter [Usual units]

$\rho_{\mathrm{s}}$ : True density $\left[\mathrm{g} . \mathrm{cm}^{-3}\right]$

$s_{A}$ : Specific surface area $\left[\mathrm{m}^{2} \cdot \mathrm{g}^{-1}\right]$

$\gamma_{s}^{d}$ : Dispersive surface energy $\left[\mathrm{mN}^{\left.-\mathrm{m}^{-1}\right]}\right.$

$\gamma_{l}^{d}$ : Liquid surface tension $\left[\mathrm{mN} . \mathrm{m}^{-1}\right]$

$\pi_{e}$ : Equilibrium spreading pressure $\left[\mathrm{mN}^{-1} \mathrm{~m}^{-1}\right]$

$\theta$ : Contact angle between solid and liquid surfaces $\left[{ }^{\circ}\right]$

$w_{S L}$ : Work of adhesion between liquid and solid phases $\left[\mathrm{mN} \cdot \mathrm{m}^{-1}\right]$

$D_{0}$ : Cut off distance [nm]

A: Hamaker constant $\left[10^{-19} \mathrm{~J}\right]$

C: Surface electrostatic charge of a particle $\left[\mu \mathrm{C} . \mathrm{m}^{-2}\right]$

$\varepsilon_{0}$ : Vacuum dielectric constant $\left[\mathrm{C}^{2} \cdot \mathrm{N}^{-1} \cdot \mathrm{m}^{-2}\right]$

$\varepsilon_{r}$ : Relative dielectric constant of the medium [-]

$d$ : Particle diameter $[\mu \mathrm{m}]$

$d_{\text {asp }}$ : Particle asperity size [nm]

$z_{0}$ : Interparticle distance $[\mathrm{Nm}]$

g: Gravity constant $\left[\mathrm{m} . \mathrm{s}^{-2}\right]$

$\varepsilon$ : Powder bed porosity [-]

$\kappa$ : Powder bed coordination number [-]

$f_{s}(x)$ : Surface fraction of size $x[-]$

$D_{s}$ : Sauter mean diameter $[\mu \mathrm{m}]$

span: Span distribution parameter [-]

$x_{0}$ : Rosin-Rammler location parameter [-]

$n$ : Rosin-Rammler spread parameter [-]

$\tau$ : Shear stress $[\mathrm{kPa}]$

$\sigma$ : Normal stress [kPa]

$\sigma_{c}$ : Pre-consolidation stress $[\mathrm{kPa}]$

$c$ : Cohesion parameter [kPa]

$\varphi$ : Angle of internal friction $\left[{ }^{\circ}\right]$

$\mu$ : Friction coefficient [-]

$\sigma_{1}$ : Major consolidation stress [kPa]

$\sigma_{3}$ : Minor consolidation stress $[\mathrm{kPa}]$

$f_{c}$ : Cohesion stress $[\mathrm{kPa}]$ 
$f f_{c}$ : Flow index [-]

$F_{e l}$ : Electrostatic force $[\mu \mathrm{N}]$

$F_{v d W}$ : Van der Waals force $[\mu \mathrm{N}]$

$W$ : Weight $[\mu \mathrm{N}]$
$B o_{g}$ : Granular Bond number [-

$B o_{g}$ : Mean granular Bond number [-]

$B o_{G}$ : Population dependent granular Bond number [-] 